\title{
ESTRATEGIAS SANCIONADORAS EN MATERIA DE CAMBIO CLIMÁTICO: LA PERSECUCIÓN PENAL DEL TRÁFICO ILEGAL DE MADERA EN LA UNIÓN EUROPEA Y EN ESPAÑA ${ }^{1}$
}

\section{SANCTIONING STRATEGIES IN CLIMATE CHANGE: ADDRESSING \\ ILLEGAL TIMBER TRADE IN THE EUROPEAN UNION AND IN SPAIN}

\author{
MARIA MARQUĖS-BANQUÉ \\ Universitat Rovira i Virgili \\ maria.marques@urv.cat
}

Fecha de recepción: 14 de octubre de 2019 / Fecha de aceptación: 4 de noviembre de 2019

RESUMEN: Partiendo de la estrecha relación entre deforestación y cambio climático, este trabajo tiene como objetivo analizar el marco sancionador derivado de la implementación normativa en los Estados miembros de la UE del artículo 19 del Reglamento (UE) n 995/2010 del Parlamento Europeo y del Consejo, de 20 de octubre de 2010, por el que se establecen las obligaciones de los agentes que comercializan madera y productos de la madera (EUTR). El objetivo es determinar en qué medida los Estados miembros han optado por el Derecho penal como estrategia sancionadora en este ámbito. Tras una breve introducción sobre los antecedentes del EUTR y el marco sancionador previsto en su artículo 19, se exponen en primer lugar los resultados del estudio sobre la implementación normativa del EUTR en los 28 Estados miembros de la UE y Noruega, indicando la naturaleza y la gravedad de las sanciones previstas en sus legislaciones nacionales. A continuación, se aborda específicamente la implementación normativa del artículo 19 del EUTR en España. En la medida

\footnotetext{
${ }^{1}$ El presente trabajo ha sido realizado en el marco del proyecto de investigación "Constitución climática global: gobernanza y derecho en un contexto complejo" (referencia DER2016-80011P), financiado por el Ministerio de Economía y Competitividad del Gobierno de España, dentro del Programa Estatal de Fomento de la Investigación Científica y Técnica de Excelencia, Subprograma Estatal de Generación del Conocimiento (Plan Estatal de Investigación Científica y Técnica y de Innovación 2013-2016).
} 
que, como se verá, España ha optado por las sanciones administrativas en la aplicación del EUTR, se apunta brevemente qué otros mecanismos existen para la persecución penal del tráfico ilegal de madera y sus productos derivados.

RESUM: Partint de l'estreta relació entre desforestació i canvi climàtic, aquest treball té com a objectiu analitzar el marc sancionador derivat de la implementació normativa en els Estats membres de la UE de l'article 19 del Reglament (UE) n` 995/2010 del Parlament Europeu i del Consell, de 20 d'octubre de 2010, pel qual s'estableixen les obligacions dels agents que comercialitzen fusta i productes de la fusta (EUTR). L'objectiu és determinar en quina mesura els Estats membres han optat pel Dret penal com a estratègia sancionadora en aquest àmbit. Després d'una breu introducció sobre els antecedents del EUTR i el marc sancionador previst en el seu article 19, s'exposen en primer lloc els resultats de l'estudi sobre la implementació normativa del EUTR en els 28 Estats membres de la UE i Noruega, indicant la naturalesa i la gravetat de les sancions previstes en les seves legislacions nacionals. A continuació, s'aborda específicament la implementació normativa de l'article 19 del EUTR a Espanya. En la mesura que, com es veurà, Espanya ha optat per les sancions administratives en l'aplicació del EUTR, s'apunta breument quins altres mecanismes existeixen per a la persecució penal del tràfic il.legal de fusta i els seus productes derivats.

ABSTRACT: Taking into consideration the link between deforestation and climate change, this paper aims to analyse the sanctioning framework derived from the implementation in the domestic legislations of EU Member States of Article 19 of Regulation (EU) No 995/2010 of the European Parliament and of the Council of 20 October 2010 laying down the obligations of operators who place timber and timber products on the market (EUTR). The aim is to determine the extent to which Member States have opted for criminal law as a sanctioning strategy in this area. Firstly, the paper briefly introduces the background of the EUTR and the sanctioning framework provided for in Article 19. Secondly, the results of the study on the regulatory implementation of the EUTR in the 28 EU Member States and Norway are presented indicating the nature and severity of the sanctions provided for in their domestic legislation. Finally, the paper 
addresses the implementation of article 19 of the EUTR in Spain. Given that Spain has opted for administrative sanctions in the application of the EUTR, the paper briefly points out what criminal mechanisms exist to tackle illegal trafficking in timber and timber products.

PALABRAS CLAVE: Tráfico ilegal de madera - Sanciones penales - Cambio climático

PARAULES CLAU: Tràfic il.legal de fusta - Sancions penals - Canvi climàtic

KEYWORDS: Illegal timber trade - Criminal sanctions - Climate change

SUMARIO: I. Introducción. II. El Reglamento (UE) n 995/2010 del Parlamento Europeo y del Consejo, de 20 de octubre de 2010, por el que se establecen las obligaciones de los agentes que comercializan madera y productos de la madera (EUTR). III. La persecución penal del tráfico ilegal de madera en la Unión Europea. 1. La implementación normativa del artículo 19 del EUTR en la Unión Europea. a) Sobre la naturaleza de las sanciones aplicables. b) Sobre la gravedad de las sanciones aplicables. 2. Breve apunte: sanciones penales más allá del EUTR. IV. La persecución penal del tráfico ilegal de madera en España. 1. La implementación normativa del artículo 19 del EUTR en España. 2. Breve apunte: sanciones penales más allá del EUTR. a) Los delitos de contrabando. b) El artículo 332 del Código penal. V. Conclusiones. VI. Bibliografía.

\section{INTRODUCCIÓN}

La relación entre bosques, biodiversidad y cambio climático está desde hace años presente en foros científicos, declaraciones políticas e iniciativas normativas y no normativas de ámbito internacional, regional y nacional. Por referirme únicamente a dos de las iniciativas más recientes en el contexto de la Unión Europea (en adelante, UE), baste citar la resolución del Parlamento Europeo, de 11 de septiembre de 2018, sobre bosques, o la todavía más reciente Comunicación de la Comisión al Parlamento Europeo, al Consejo, al Comité Económico y Social Europeo y al Comité de las Regiones, de 23 de julio de 2019, cuyo título deja poco lugar a dudas sobre el posicionamiento de la Comisión: 
"Intensificar la actuación de la UE para proteger y restaurar los bosques del mundo"2 $\mathrm{y}^{3}$.

En estos documentos, como en tantos otros de organizaciones e instituciones de muy distinta índole, se recuerda que "los bosques con diversidad biológica contribuyen significativamente a la mitigación del cambio climático y a la adaptación al mismo, así como a la conservación de la biodiversidad", señalando, además, que "la deforestación y la degradación de los bosques son la segunda causa de origen humano de las emisiones de carbono y son responsables de casi el $20 \%$ de las emisiones mundiales" ${ }^{4}$. Se subraya, así mismo, la importancia y la urgencia de la mejora de la gestión sostenible de los bosques para la Agenda 2030 de las Naciones Unidas para el Desarrollo Sostenible, "ya que los bosques desempeñan un papel multifuncional que favorece la consecución de la mayoría de los Objetivos de Desarrollo Sostenible"5. El objetivo de la Agenda 2030 de detener la deforestación se reitera en el Acuerdo de París sobre cambio climático, firmado el 22 de abril de 2016 y ratificado por la UE el 5 de octubre de $2016^{6}$.

En este escenario, la lucha contra los llamados delitos forestales debe ser considerada un elemento fundamental de la estrategia sancionadora en materia de cambio climático. La expresión "delitos forestales", como traducción de la expresión inglesa "forest crime" (o "forestry crime"), debe entenderse en sentido

\footnotetext{
2 Vid. la Resolución del Parlamento Europeo, de 11 de septiembre de 2018, sobre la gestión transparente y responsable de los recursos naturales en los países de desarrollo: los bosques (2018/2003(INI)), P8_TA (2018)0333. Disponible en: <http://www.europarl.europa.eu/doceo/document/TA-8-2018-0333_ES.html> [última consulta, 30 de septiembre de 2019].

3 Vid. La Comunicación de la Comisión al Parlamento Europeo, al Consejo, al Comité Económico y Social Europeo y al Comité de las Regiones, de 23 de julio de 2019, cuyo título deja poco lugar a dudas sobre el posicionamiento de la Comisión: "Intensificar la actuación de la UE para proteger y restaurar los bosques del mundo. Disponible en: < https://ec.europa.eu/transparency/regdoc/rep/1/2019/ES/COM-2019-352-F1-ES-MAIN-PART1.PDF> [última consulta, 11 de octubre de 2019].

${ }^{4}$ Vid. la Resolución del Parlamento Europeo, de 11 de septiembre de 2018, sobre la gestión transparente y responsable de los recursos naturales en los países de desarrollo: los bosques cit., considerandos letras $\mathrm{A}$ e I.

5 Vid. La Comunicación de la Comisión al Parlamento Europeo, al Consejo, al Comité Económico y Social Europeo y al Comité de las Regiones, de 23 de julio de 2019, cuyo título deja poco lugar a dudas sobre el posicionamiento de la Comisión: "Intensificar la actuación de la UE para proteger y restaurar los bosques del mundo, cit. p. 2.

${ }_{6}$ Vid. el articulo 5 del Acuerdo de París, DO L 282 de 19.10.2016, p. 4/18. Disponible en: $<$ https://eur-lex.europa.eu/legal-content/ES/TXT/?uri=CELEX:22016A1019(01)> [última consulta, 11 de octubre de 2019].
} 
amplio. Comprende todas las conductas relativas a la cosecha, tala, transporte, procesamiento y comercio de la madera. En ocasiones, se utiliza también para referirse al conjunto de delitos conexos que pueden cometerse tanto en los países de origen, como de tránsito y de destino de la madera, en contextos de criminalidad transnacional (evasión fiscal, corrupción, falsificación de documentos, blanqueo de capitales, así como los delitos cometidos contra las personas defensoras del medio ambiente). En los delitos forestales, interviene además la delincuencia ambiental organizada, cuando se dan las condiciones propias del crimen organizado ${ }^{7}$.

Debe de tenerse presente que, según un informe conjunto de INTERPOL y el Programa de Medio Ambiente de las Naciones Unidas, la madera talada ilegalmente supone entre el $10 \%$ y el $30 \%$ del volumen total del mercado maderero mundial, y se estima que, en algunos países tropicales, entre el 50\% y el $90 \%$ de la madera tiene su procedencia de talas ilegales ${ }^{8}$.

El presente trabajo tiene como objeto analizar el marco sancionador derivado de la implementación normativa en los Estados miembros de la UE del artículo 19 del Reglamento (UE) n 995/2010 del Parlamento Europeo y del Consejo, de 20 de octubre de 2010, por el que se establecen las obligaciones de los agentes que comercializan madera y productos de la madera, conocido como Reglamento europeo de la madera o EUTR por sus siglas en inglés ("EU Timber Regulation"). El objetivo es determinar en qué medida los Estados miembros han optado por el Derecho penal como estrategia sancionadora en este ámbito.

Tras una breve introducción sobre los antecedentes del EUTR y el marco sancionador previsto en su artículo 19, se expondrán en primer lugar los resultados del estudio sobre la implementación normativa del EUTR en los 28 Estados miembros de la UE y Noruega, indicando la naturaleza y la gravedad de las sanciones previstas en sus legislaciones nacionales. No es objeto de este trabajo el estudio sobre la aplicación práctica de las mismas. A continuación, se

\footnotetext{
7 Vid. una relación detallada de los distintos delitos relacionados con los bosques en UNODC, Herramientas para el análisis de los delitos contra la vida silvestre y los bosques, 2012. Disponible en: < https://www.unodc.org/documents/Wildlife/Toolkit_s.pdf> [última consulta, 9 de octubre de 2019].

8 Vid. UNEP e INTERPOL. La crisis de delitos contra el medio ambiente, 2014, p. 8. Disponible en: <https://www.interpol.int/Crimes/Environmental-crime/Forestry-crime> [última consulta, 9 de octubre de 2019].
} 
abordará específicamente la implementación normativa del artículo 19 del EUTR en España. En la medida que, como se verá, España ha optado por las sanciones administrativas en la aplicación del EUTR, se apuntará brevemente qué otros mecanismos existen para la persecución penal del tráfico ilegal de madera y sus productos derivados.

\section{EL REGLAMENTO (UE) № 995/2010 DEL PARLAMENTO EUROPEO Y DEL CONSEJO, DE 20 DE OCTUBRE DE 2010, POR EL QUE SE ESTABLECEN LAS OBLIGACIONES DE LOS AGENTES QUE COMERCIALIZAN MADERA Y PRODUCTOS DE LA MADERA (EUTR).}

En 2002, el Sexto Programa de Acción Comunitario en Materia de Medio Ambiente (Decisión no 1600/2002/CE del Parlamento Europeo y del Consejo, de 22 de julio de 2002), estableció, como actuación prioritaria, estudiar las posibilidades de adoptar medidas activas de prevención y lucha contra la comercialización de madera aprovechada ilegalmente, así como la de proseguir la participación activa de la Unión y de los Estados miembros en la puesta en práctica de las resoluciones y los acuerdos adoptados a escala regional y mundial sobre cuestiones relacionadas con los bosques ${ }^{9}$.

En consonancia con ello, la UE adoptó en 2003 un plan de acción sobre la aplicación de las leyes, gobernanza y comercio forestales, conocido como FLEGT por sus siglas en inglés ("Forest Law Enforcement, Governance and Trade") ${ }^{10}$, para abordar el problema global de la tala ilegal y el comercio asociado a esta práctica.

El Plan de Acción FLEGT contempla tanto medidas relativas al consumo (incremento de la demanda de madera legal) como a la producción (fomento de

\footnotetext{
9 Decisión n 1600/2002/CE del Parlamento Europeo y del Consejo, de 22 de julio de 2002, por la que se establece el Sexto Programa de Acción Comunitario en Materia de Medio Ambiente. Disponible en: <https://eur-lex.europa.eu/legal-content/ES/ALL/?uri=CELEX:32002D1600> [última consulta, 8 de julio de 2019].

${ }_{10}$ Comunicación de la Comisión al Consejo y al Parlamento Europeo Aplicación de las leyes, gobernanza y comercio forestales (FLEGT). Propuesta de Plan de Acción de la Unión Europea, COM (2003) 251 final, 21 de mayo de 2003. Disponible en: <https://eur-lex.europa.eu/legalcontent/ES/TXT/PDF/?uri=CELEX:52003DC0251\&from=EN> [última consulta, 8 de julio de 2019].
} 
la producción de madera legal en los países en desarrollo). Con relación a estas últimas, especial relevancia tiene el establecimiento de los llamados Acuerdos Voluntarios de Asociación (en adelante, AVA), que son acuerdos comerciales bilaterales jurídicamente vinculantes entre la UE y terceros países exportadores de madera, con el fin de mejorar la gobernanza forestal y el cumplimiento de las leyes. Uno de los elementos clave es el establecimiento de un sistema de licencias para asegurar la procedencia legal de la madera y productos de la madera importados por la UE, regulado por el Reglamento № 2173/2005 del Consejo, de 20 de diciembre, relativo al establecimiento de un sistema de licencias de FLEGT para las importaciones de madera en la Comunidad Europea ${ }^{11}$.

En el marco del Plan FLEGT, siete años más tarde la UE adoptó el Reglamento (UE) n 995/2010 del Parlamento Europeo y del Consejo, de 20 de octubre de 2010, por el que se establecen las obligaciones de los agentes que comercializan madera y productos de la madera (EUTR), aplicable a partir del 3 de marzo de $2013^{12}$. De acuerdo con el considerando núm. (8) del Reglamento, la magnitud y urgencia del problema hacen necesario "apoyar activamente la lucha contra la tala ilegal y el comercio asociado a esa práctica, completar y reforzar la iniciativa de los acuerdos de asociación voluntarios FLEGT y mejorar las sinergias entre las políticas de conservación de los montes y aquellas dirigidas a alcanzar un nivel elevado de protección del medio ambiente, incluso en relación con la lucha contra el cambio climático y la pérdida de biodiversidad". El Reglamento permite abordar el problema desde la perspectiva de la demanda y, en la medida que la madera con licencias FLEGT y CITES se considera aprovechada legalmente y, por ello, automáticamente conforme al EUTR, el Reglamento europeo de la madera es también una medida complementaria de fomento de los AVA y del sistema de licencias FLEGT y CITES $^{13}$.

\footnotetext{
${ }^{11}$ Reglamento no 2173/2005 del Consejo, de 20 de diciembre, relativo al establecimiento de un sistema de licencias de FLEGT para las importaciones de madera en la Comunidad Europea Disponible en: https://www.boe.es/buscar/doc.php?id=DOUE-L-2005-82629 [última consulta, 8 de julio de 2019].

12 Reglamento (UE) n' 995/2010 del Parlamento Europeo y del Consejo, de 20 de octubre de 2010, por el que se establecen las obligaciones de los agentes que comercializan madera y productos de la madera. Disponible en: <https://eur-lex.europa.eu/legalcontent/ES/TXT/?uri=CELEX:32010R0995> [última consulta, 8 de julio de 2019].

${ }_{13}$ Aunque ya hay quien ha advertido que la exención de las licencias CITES tiene también desventajas, pues entraña un mayor riesgo de fraude y corrupción en la emisión de estos
} 
EI EUTR establece como obligaciones de los agentes que comercialicen por primera vez madera y productos de la madera en el mercado de la UE:

1. La prohibición de comercialización de madera aprovechada ilegalmente o de productos derivados de esa madera. De acuerdo con el art. 2 EUTR, se entenderá por madera aprovechada ilegalmente aquella aprovechada en incumplimiento de la legislación aplicable del país de aprovechamiento.

2. La obligación de ejercer la diligencia debida cuando comercialicen madera o productos de esa madera. Con este fin, deberán adoptar un sistema de diligencia debida, cuyos elementos principales se recogen en el art 6 EUTR, que minimice el riesgo de comercializar en el mercado interior madera aprovechada ilegalmente y productos derivados de esa madera.

3. La obligación de trazabilidad, lo cual significa la capacidad de los comerciantes de identificar en toda la cadena de suministro: a) a los agentes o comerciantes que hayan suministrado la madera y los produces de la madera; b) cuando proceda, a los comerciantes a los que hayan suministrado madera y productos de la madera.

Se establece además la obligación de los Estados miembros de designar una o varias autoridades competentes, responsables de la aplicación del Reglamento, que deberán realizar controles oficiales a los agentes $\mathrm{y}$, habida cuenta del carácter internacional de la tala ilegal y del comercio asociado a esa práctica, deberán cooperar entre ellas y con las autoridades administrativas de terceros países y la Comisión Europea.

Cabe destacar que como señala el Informe bienal de la Comisión al Parlamento Europeo y al Consejo para el período de marzo de 2015 a febrero de 2017, "el EUTR es el primer instrumento jurídico a escala de la UE que incluye la obligación de diligencia debida, un principio fundamental para la responsabilidad empresarial sostenible que está en consonancia con los Principios Rectores de las Naciones Unidas (UNGP) sobre las empresas y los derechos humanos"14.

permisos. En este sentido, vid. Jade Saunders, Rosalind Reeve, The EU Timber Regulation and CITES, Energy, Environment and Resources PP EER 2014/08, Chatham House, London, 2014, p.24. Disponible en: < https://www.chathamhouse.org/publications/papers/view/199158\#> [última consulta, 11 de octubre de 2019].

14 Vid. el Informe de la Comisión al Parlamento Europeo y al Consejo. Reglamento (UE)

n. ${ }^{\circ}$ 995/2010 del Parlamento Europeo y del Consejo, de 20 de octubre de 2010, por el que se 
En materia de sanciones, objeto específico de este estudio, el artículo 19 EUTR establece:

"1. Los Estados miembros establecerán el régimen de sanciones aplicable en caso de incumplimiento de las disposiciones del presente Reglamento y adoptarán todas las medidas necesarias para garantizar la ejecución de dicho régimen.

2. Las sanciones establecidas deberán ser efectivas, proporcionadas y disuasorias y podrán incluir, entre otras medidas:

a) multas proporcionales al perjuicio medioambiental, al valor de la madera o de los productos de la madera de que se trate y a las pérdidas fiscales y a los perjuicios económicos resultantes de la infracción, calculándose la cuantía de dichas multas de forma que los infractores se vean efectivamente privados de los beneficios económicos derivados de las infracciones que hayan cometido, sin perjuicio del derecho legítimo a ejercer una profesión, e incrementándose gradualmente dicha cuantía por comisión retirada de infracciones graves;

b) la incautación de la madera y de los productos de la madera de que se trate;

c) la suspensión inmediata de la autorización de actividad comercial.

3. Los Estados miembros notificarán esas disposiciones a la Comisión y la informarán sin demora de cualquier modificación posterior de las mismas".

Como puede apreciarse, el EUTR no determina el carácter penal o administrativo de las sanciones que deben establecer los Estados miembros, limitándose a indicar que deberán ser "efectivas, proporcionadas y disuasorias". Esta expresión, adoptada en 1989 por la jurisprudencia del TJCE en el llamado "caso del maíz griego"15 y utilizada posteriormente en múltiples ocasiones, deja a los

establecen las obligaciones de los agentes que comercializan madera y productos de la madera (el Reglamento de la UE sobre la madera). Informe bienal para el período de marzo de 2015 a febrero de 2017, COM/2018/668 final. Disponible en: <https://eur-lex.europa.eu/legalcontent/ES/TXT/HTML/?uri=CELEX:52018DC0668\&from=ES> [última consulta el 8 de julio de 2019]. Los Principios Rectores fueron adoptados por el Consejo de Derechos Humanos de la ONU en su resolución 17/4, de 16 de junio de 2011. Pueden consultarse en: <https://www.ohchr.org/documents/publications/guidingprinciplesbusinesshr_sp.pdf> [última consulta, 27 de septiembre de 2019].

15 Sentencia del TJCE, de 21 de septiembre de 1989, asunto 68/88. 
Estados miembros la decisión acerca de la naturaleza de las sanciones a aplicar para garantizar el cumplimiento del Derecho de la UE.

Sintetizando necesariamente mucho, en el ámbito del Derecho penal ambiental europeo, la idea de eficacia de la sanción ha sido interpretada en términos de consecución del fin de la norma, de prevención general y especial, pero también desde el punto de vista de reparación del daño causado y de prevención del daño futuro ${ }^{16}$. Sobre el carácter proporcionado de las mismas, no encontramos ninguna especificidad. Se refiere, como es sabido, a la necesaria proporcionalidad entre la sanción y el resultado del delito. Es quizás el carácter disuasorio de la sanción el aspecto que ha llevado a más controversia, pues no existe consenso con relación al recurso prioritario al Derecho penal ni con la consideración de la sanción penal como la única con capacidad disuasoria en este ámbito ${ }^{17}$. Los argumentos contrarios a la introducción de sanciones penales en materia ambiental son argumentos conocidos, en la medida que pueden enmarcarse en la línea que reivindica el principio de "ultima ratio" del Derecho penal y el recurso a mecanismos alternativos considerados igualmente disuasorios y eficaces ${ }^{18}$. Además de los clásicos argumentos que abogan por la contención en el uso del Derecho penal, algunos autores hacen referencia, en el marco de esta discusión, a los datos empíricos disponibles sobre la aplicación de los delitos ambientales y su valoración desde una perspectiva del análisis económico del Derecho. Así, se hace hincapié en que en determinados Estados miembros -en los que el principio de oportunidad tiene más recorrido- se observa

\footnotetext{
16 Vid. Michael Faure, "The implementation of the environmental crime Directives in Europe", en J. Gerardu, D. Grabiel, MR. Koparova, K. Markowitz y D. Zaelke (eds), 9th International Conference on Environmental Compliance and Enforcement, Washington, INECE, 2011, p. 366. Del mismo autor, vid. extensamente: "Effective, proportional and dissuasive penalties in the implementation of the Environmental Crime and Shipsource Pollution Directives: Questions and Challenges", European Energy and Environmental Law Review, 19:6 (2010), p. 256 ss.

17 Vid. una postura particularmente crítica en Michael Faure, "European Environmental Criminal Law: Do we really need it?", European Energy and Environmental Law Review, 13:1 (2004), p. 18 ss; Michael Faure, Katarina Svatikova, "Criminal or administrative law to protect the environment? Evidence from Western Europe", Journal of Environmental Law, $24: 2$ (2012), p. 253 ss.

${ }^{18}$ Postura coherente con los principios fundamentales de la política criminal europea, declarados tanto en documentos institucionales (por ejemplo, la Resolución del Parlamento Europeo, de 22 de mayo de 2012, sobre un enfoque de la UE acerca del Derecho penal P7_TA (2012) 0208), como de naturaleza académica (así, el "Manifiesto sobre la política criminal europea", impulsado por un grupo de profesores de Derecho penal en 2009, disponible en: <http://www.crimpol.eu/manifesto/> [última consulta, 27 de septiembre de 2019], que consta de una versión actualizada publicada en European Criminal Law Review, 1 (2011), p. 86 ss).
} 
cómo la Fiscalía tiende a no perseguir penalmente aquellos delitos ambientales menos graves, debido al elevado coste del proceso penal. En consecuencia, en el supuesto de no existir sanción alternativa a la penal, no únicamente se pone de manifiesto la ineficacia instrumental de estos delitos sino que queda en entredicho el efecto preventivo de la pena ${ }^{19}$. Características, todas ellas, propias del Derecho penal simbólico.

En el otro extremo, aquellos que sostienen la introducción de penas privativas de libertad en este ámbito, aluden, por ejemplo, al perfil de "autor racional" de los delitos ambientales. Se indica que este perfil de autor suele hacer un análisis coste-beneficio del delito, máxime cuando actúa en el marco de una persona jurídica y las sanciones son pecuniarias, como sería el caso de la multa proporcional sugerida por el artículo 19 EUTR. Se apunta que la persona física condenada a una multa puede ser indemnizada por la persona jurídica, repercutiendo ésta la sanción en sus clientes, accionistas u otras terceras partes, algo que desde luego no puede ocurrir en el caso de las penas privativas de libertad ${ }^{20}$.

Este debate ha tenido lugar muy significativamente con relación a la Directiva 2008/99/CE relativa a la protección del medio ambiente mediante el Derecho Penal, que, si bien obligó por primera vez a que las sanciones que debían prever los Estados miembros para las personas físicas fueran sanciones penales, no estableció un marco de penas mínimas y/o máximas para cada uno de los delitos contemplados en esta Directiva, acogiéndose a la fórmula de sanciones penales "efectivas, proporcionadas y disuasorias" (si bien hay que señalar que, en este caso, la traducción al español de la Directiva utiliza el término "eficaces" en lugar de "efectivas"), dando lugar, como he tenido ocasión de analizar de forma exhaustiva en otro lugar, a significativas disparidades entre los distintos Estados

\footnotetext{
19 Vid. el enfoque económico en Michael Faure, "The revolution in environmental criminal law in Europe", Virginia Environmental Law Journal, 35:2 (2017), p. 338ss; Michael Faure, Katarina Svatikova, "Criminal or Administrative Law to protect the environment? Evidence from Western Europe", cit. p. 253 ss.

20 Sobre este debate vid. Jacob Öberg, "Criminal sanctions in the field of EU Environmental Law", New Journal of European Criminal Law, 2:4, (2011), p. 405 ss.
} 
miembros en cuanto a la tipología y a la gravedad de las penas previstas en las legislaciones nacionales para los delitos previstos en la Directiva ${ }^{21} y^{22}$.

Hay que recordar que una de las razones por las que es relevante el análisis del marco de sanciones penales en este ámbito, es la eventual aplicabilidad de la Convención de las Naciones Unidas contra la delincuencia organizada transnacional (2004), que requiere que los delitos sean punibles con una pena de privación de libertad máxima de al menos cuatro años ${ }^{23}$. La armonización de las sanciones suele ser considerada, además, un elemento clave en la lucha contra la criminalidad ambiental organizada transnacional por aquellas organizaciones e instituciones que trabajan con una perspectiva más práctica y conocen las dinámicas de los grupos criminales organizados y las dificultades de persecución de estos delitos sobre el terreno ${ }^{24}$.

En el siguiente apartado se abordará el análisis de la implementación normativa del EUTR en los distintos Estados miembros de la UE, con el fin de identificar la naturaleza y gravedad de las sanciones establecidas, el nivel de armonización alcanzado y, en definitiva, la estrategia sancionadora seguida en el caso del tráfico ilegal de madera y sus productos derivados en la UE. Ello permitirá comprobar si estaba justificado el escepticismo con el que se manifestaron los primeros autores que abordaron el marco sancionador del EUTR ${ }^{25}$.

\footnotetext{
${ }^{21}$ Vid. un estudio comparativo de las sanciones en Maria Marquès-Banqué, "The utopia of the harmonization of legal frameworks to fight against transnational organized environmental crime", Sustainability, Volume 10, Issue 10, 3576 (Special issue: Environmental Law for Sustainability 2018). Disponible en: <https://www.mdpi.com/2071-1050/10/10/3576> [última consulta, 8 de julio de 2019].

22 La falta de una mayor concreción de las sanciones se explica por la base jurídica de la Directiva, aprobada con anterioridad al Tratado de Lisboa. Vid. un análisis de la Directiva en Maria Marquès-Banqué, "Protección penal del medio ambiente en la Unión Europea. Luces y sombras", en P.M. De la Cuesta Aguado et al (coord), Liber amicorum: estudios jurídicos en homenaje al profesor doctor Juan Ma. Terradillos Basoco, Tirant lo Blanch, Valencia, 2018, pp. 1257-1270.

23 Convención de las Naciones Unidas contra la delincuencia organizada transnacional. Disponible en: <https://www.unodc.org/documents/treaties/UNTOC/Publications/TOC\%20Convention/TOCebo ok-s.pdf> [última consulta, 8 de julio de 2019].

24 Vid. por todos, Global Initiative Against Transnational Organized Crime, Tightening the Net: Toward a Global Legal Framework on Transnational Organized Environmental Crime, 2015, p.34. Disponible en: $\quad$ https://www.unodc.org/documents/congress/backgroundinformation/NGO/GIATOC-Blackfish/GIATOC_-_Tightening_the_Net.pdf> [última consulta, $30 \mathrm{de}$ septiembre de 2019].

${ }^{25}$ Vid. Yulia Evashova, "How effective is the New Timber Regulation in the Fight against Illegal Logging?", Review of European Community and International Environmental Law 20 (3) 2011, pp. 296-298.
} 


\section{LA PERSECUCIÓN PENAL DEL TRÁFICO ILEGAL DE MADERA EN LA UNIÓN EUROPEA}

\section{La implementación normativa del artículo 19 EUTR en la Unión Europea}

En este apartado se expondrán los resultados del estudio sobre la implementación del artículo 19 EUTR en las legislaciones nacionales de los 28 Estados miembros de la UE y Noruega.

El análisis se ha realizado sobre la base de las siguientes fuentes documentales:

1) El estudio realizado durante el primer semestre del año 2018, del sistema de sanciones aplicables en cada uno de los Estados miembros como consecuencia del EUTR ${ }^{26}$. Para recabar la información, se contactó directamente con las autoridades competentes de los Estados miembros. A la vista del bajo nivel de respuesta o del contenido insuficiente de las respuestas obtenidas, se optó por identificar el marco jurídico de cada Estado miembro y solicitar la verificación en una segunda comunicación con las autoridades competentes. Únicamente se obtuvo verificación por parte de Irlanda, Suecia y el Reino Unido.

2) El informe bienal para el período de marzo de 2015 a febrero de 2017 de la Comisión al Parlamento Europeo y al Consejo sobre la aplicación del EUTR, publicado el 5 de octubre de 2018 (en adelante, el Informe Bienal de la Comisión $)^{27}$.

3) El análisis elaborado por PNUMA-CMVC Background analysis of the 20152017 national biennial reports on the implementation of the European Union's Timber Regulation (Regulation EU No 995/2010). UNEP-WCMC, Cambridge, $2018^{28}$.

\footnotetext{
${ }^{26}$ Hay que agradecer y reconocer la tarea realizada en este punto por el Sr. Jaume Hernández Hernández, beneficiario durante el curso académico 2017-2018 de una beca de colaboración de estudiantes en departamentos universitarios del Ministerio de Educación, Cultura y Deporte.

27 Informe de la Comisión al Parlamento Europeo y al Consejo. Reglamento (UE) n. ${ }^{\circ}$ 995/2010 del Parlamento Europeo y del Consejo, de 20 de octubre de 2010, por el que se establecen las obligaciones de los agentes que comercializan madera y productos de la madera (el Reglamento de la UE sobre la madera). Informe bienal para el período de marzo de 2015 a febrero de 2017, COM/2018/668 final, cit., passim.

28 PNUMA-CMVC, Background analysis of the 2015-2017 national biennial reports on the implementation of the European Union's Timber Regulation (Regulation EU No 995/2010).
} 
4) Los informes bienales de los Estados miembros sobre aplicación del EUTR, enviados a la Comisión Europea en $2017^{29}$.

5) Los informes sobre la implementación del EUTR elaborados por ClientEarth con relación a Alemania, Austria, Bélgica, Bulgaria, Dinamarca, Finlandia, Francia, Italia, Países Bajos, Polonia, Romania y Reino Unido ${ }^{30}$.

Los resultados se referirán a la naturaleza y a la gravedad de las sanciones aplicables. Como en todo análisis de estas características, en el transcurso del mismo se han planteado algunas limitaciones y tomado algunas opciones que serán indicadas oportunamente.

\section{a) Sobre la naturaleza de las sanciones aplicables}

La primera cuestión relevante cuando se analiza la respuesta sancionadora de los Estados miembros en caso de incumplimiento de las disposiciones del EUTR es determinar la naturaleza penal o administrativa de las sanciones previstas en las legislaciones nacionales. A los efectos de este estudio, se han considerado únicamente las penas privativas de libertad y las sanciones pecuniarias. Así, se considera que un Estado miembro ha optado por sanciones penales y administrativas, cuando, además de sanciones penales (pena privativa de libertad y/o multa penal), se prevén multas administrativas. Por consiguiente, no se toma en consideración la existencia de medidas de otro carácter o naturaleza (véase más adelante las observaciones con relación a Luxemburgo y Malta).

El Informe Bienal de la Comisión, elaborado a partir de la información enviada por los 28 Estados miembros y Noruega, señala que las sanciones pueden ser tanto administrativas como penales en 13 países, solo administrativas en 10 países y únicamente penales en 2 países, indicando que fueron 4 los países que

\footnotetext{
UNEP-WCMC, Cambridge, $2018 . \quad$ Disponible en: <http://ec.europa.eu/environment/forests/pdf/WCMC\%20EUTR\%20analysis\%202017.pdf> [última consulta, 8 de julio de 2019].

${ }_{29}$ Disponibles en: <http://ec.europa.eu/environment/forests/eutr_report.htm> [última consulta, 8 de julio de 2019].

30 Disponibles en:< https://www.clientearth.org/eu-timber-regulation-implementation-andenforcement-updates/> [última consulta, 8 de julio de 2019].
} 
no especificaron la naturaleza de las sanciones en sus respectivos informes nacionales ${ }^{31}$.

Sin embargo, ni el Informe Bienal de la Comisión ni el informe elaborado por el Centro Mundial de Vigilancia de la Conservación (CMVC) del Programa de las Naciones Unidas para el Medio Ambiente (PNUMA), que ofrece un análisis más detallado de los informes de los Estados miembros, especifican qué países optaron por cada una de las alternativas.

Es por ello que se han analizado los informes originales de los Estados miembros, los informes elaborados por ClientEarth y se ha solicitado información complementaria a Chipre, Luxemburgo, Dinamarca y la República de Croacia, habiendo obtenido únicamente respuesta de los dos primeros países.

Debe advertirse que los resultados que se presentan a continuación en forma de mapa pueden diferir levemente del Informe Bienal de la Comisión, siendo difícil identificar los eventuales errores en uno u otro estudio. Este hecho es consecuencia de una limitación habitual en los análisis comparativos de la aplicación del Derecho de la Unión Europea, cuando las fuentes disponibles son fundamentalmente los informes de la Comisión Europea (los cuales no siempre ofrecen datos desagregados) y los informes nacionales de los Estados miembros (muchas veces incompletos o con remisión a normas propias de las que no se dispone de traducción).

\footnotetext{
${ }^{31}$ Informe de la Comisión al Parlamento Europeo y al Consejo. Reglamento (UE) n. ${ }^{\circ}$ 995/2010 del Parlamento Europeo y del Consejo, de 20 de octubre de 2010, por el que se establecen las obligaciones de los agentes que comercializan madera y productos de la madera (el Reglamento de la UE sobre la madera). Informe bienal para el período de marzo de 2015 a febrero de 2017, cit., p. 4.
} 


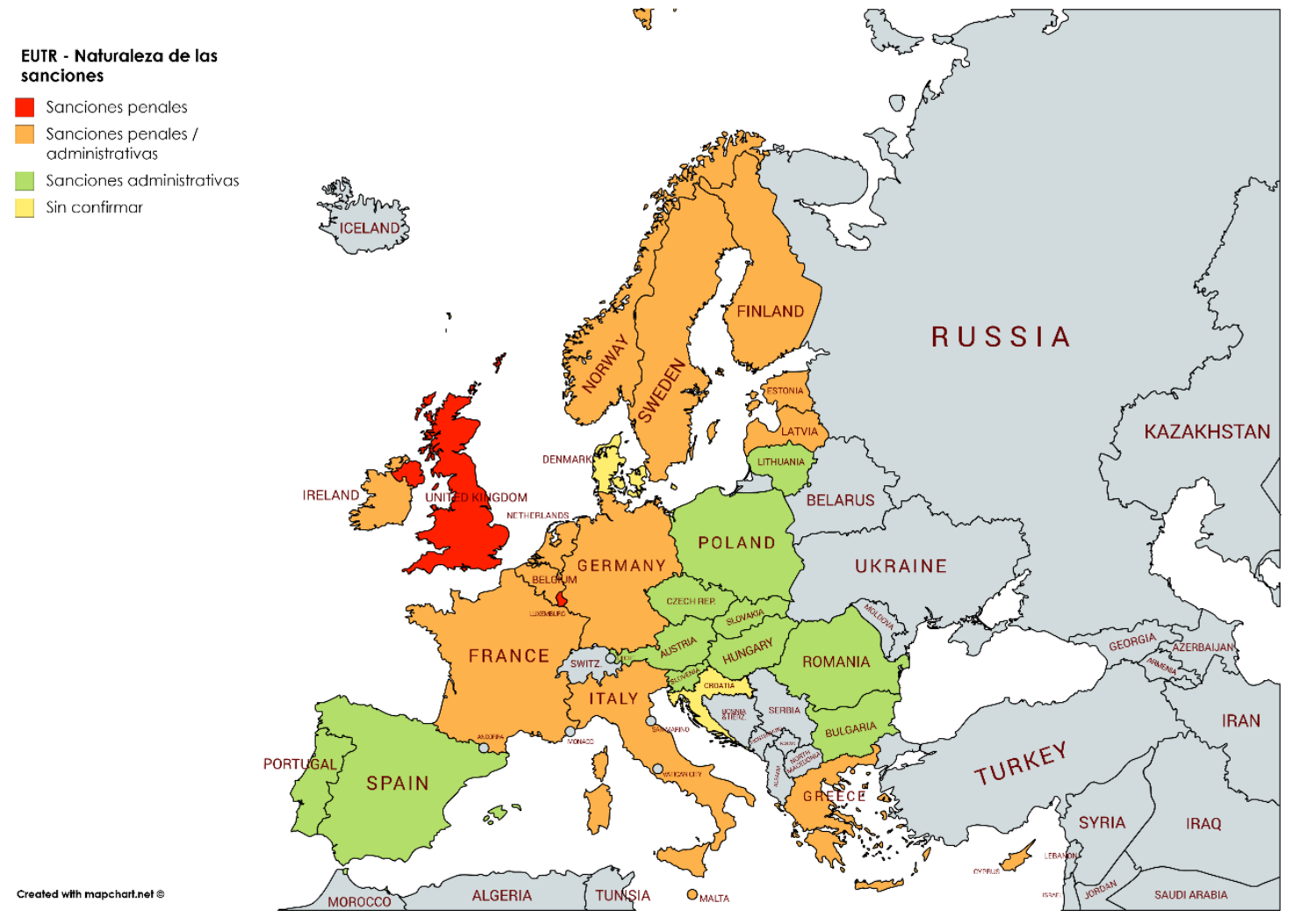

Figura 1 (elaboración propia): Naturaleza de las sanciones previstas por los Estados miembros por infracción del EUTR.

Como puede observarse, los Estados miembros han optado mayoritariamente, o bien por una combinación de sanciones penales y administrativas (14 países), o bien por sanciones administrativas (11 países), siendo minoritaria la opción por sanciones penales exclusivamente (2 países).

Con relación a los resultados obtenidos, debe hacerse todavía alguna consideración:

1) El análisis del informe nacional enviado por Lituania a la Comisión, hace sospechar que las sanciones establecidas no son por infracción específica del EUTR, sino por infracciones sobre tala ilegal en general.

2) En el caso de Luxemburgo, si bien la respuesta a la petición de información adicional fue en el sentido de afirmar la naturaleza tanto penal como administrativa de sus sanciones, del análisis de la legislación facilitada se ha concluido que, por sanción administrativa, la persona contactada entendía 
también lo que en su legislación califican de "medidas administrativas", como puede ser la retirada de la madera ilegal del mercado. En la medida que, en su legislación, las sanciones pecuniarias están expresamente consideradas como penales, se ha optado por clasificar a Luxemburgo entre los países que han optado exclusivamente por sanciones penales.

3) Finalmente, Malta, país clasificado entre los que optan por sanciones penales y administrativas, prevé, como alternativa, la adopción de medidas en la jurisdicción civil en los supuestos en que se haya llegado a un acuerdo. Entre estas medidas, se encuentra la posibilidad de imposición de una multa. Esta particularidad es consecuencia, como es sabido, de la distinta configuración de los sistemas jurídicos basados en el common law.

\section{b) Sobre la gravedad de las sanciones aplicables}

La información disponible no permite hacer un análisis, por separado, de la gravedad de las sanciones penales y administrativas aplicables por infracción del EUTR. Las fuentes disponibles (ya sea el Informe Bienal de la Comisión, los informes nacionales remitidos por los Estados miembros o los estudios complementarios), no permiten dilucidar, en todos los casos, la naturaleza penal o administrativa de las multas.

Es por ello que, a los efectos de este estudio, se ha optado por analizar la gravedad de las sanciones privativas de libertad y, con relación a las sanciones pecuniarias, remitirnos a los resultados del Informe Bienal de la Comisión.

\section{i. Sanciones privativas de libertad}

A continuación, se presentan los resultados del análisis de las penas máximas privativas de libertad establecidas por los países que han optado por el recurso al Derecho penal para sancionar las infracciones del EUTR, ya sea de forma exclusiva, ya sea de forma combinada con el Derecho administrativo sancionador, siempre que hayan sido indicadas en los informes nacionales. 

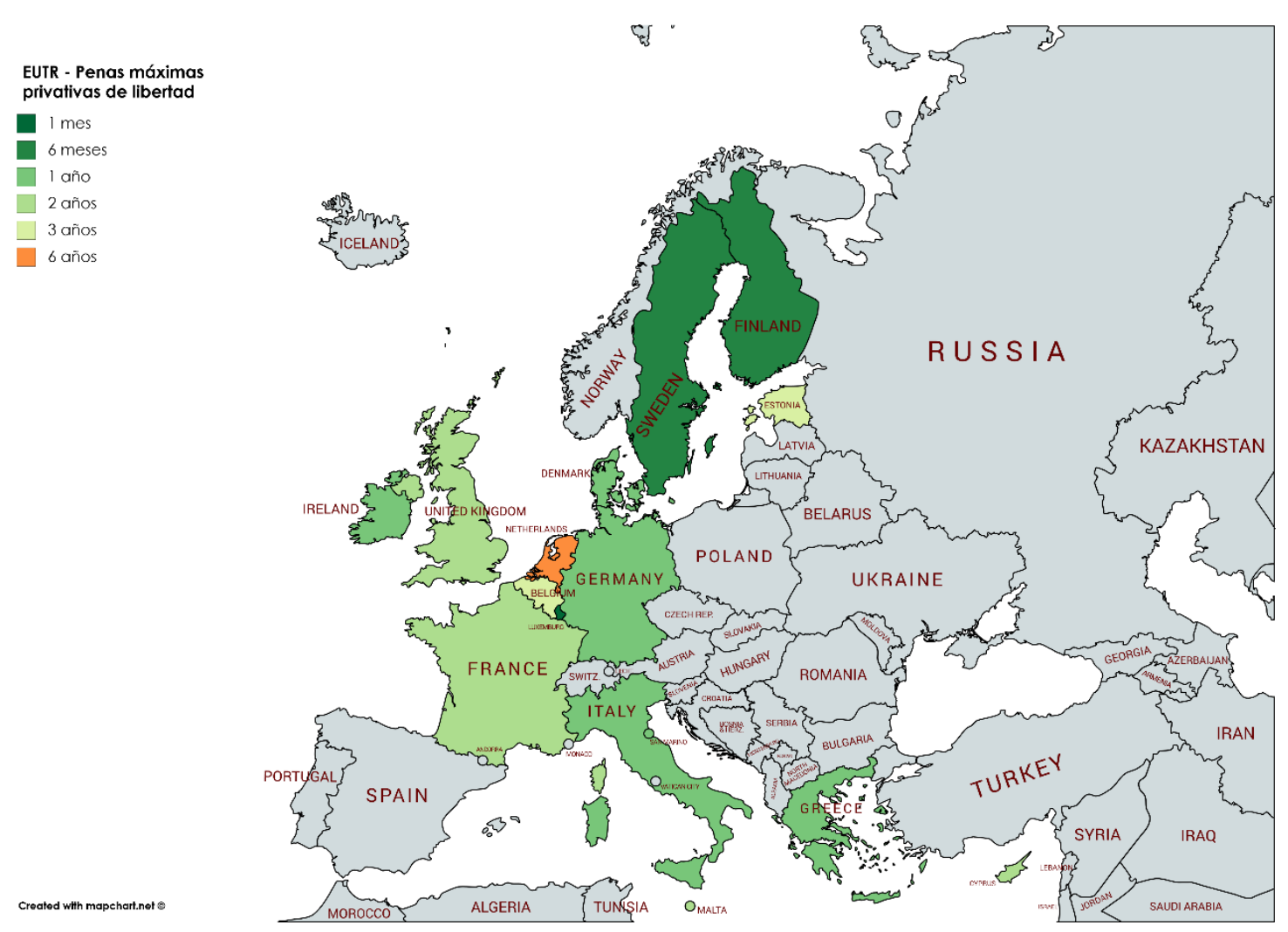

Figura 2 (elaboración propia): Penas máximas privativas de libertad previstas por los Estados miembros por infracción del EUTR.

Como puede observarse, las penas máximas privativas de libertad oscilan entre 1 mes (Luxemburgo) y 6 años (Países Bajos), situándose la mayoría de países en una horquilla que va de 1 a 3 años de prisión.

Estos resultados deben tomarse, sin embargo, de forma meramente indicativa. Como en el epígrafe anterior, cabe hacer algunas consideraciones:

1) La pena máxima privativa de libertad prevista por Finlandia es de 6 meses con relación a la madera importada, pero se incrementa hasta los 2 años en caso de madera nacional. No se ha trasladado al mapa de resultados la pena más elevada, por centrar aquí el interés en la madera importada.

2) En el mismo sentido, Letonia especifica en su informe nacional la posibilidad de imponer una pena privativa de libertad de hasta 8 años en el caso de tala ilegal a nivel nacional. Para el resto de supuestos, el informe nacional refiere sanciones penales de carácter pecuniario 0 bien sanciones 
administrativas. No se ha trasladado al mapa de resultados la previsión de la pena privativa de libertad por entender que, en este caso, no estaríamos estrictamente ante una infracción del EUTR.

3) Grecia eleva la pena a 2 años en caso de reiteración delictiva.

4) Suecia prevé la pena máxima de 6 meses de privación de libertad para las infracciones del EUTR, pero indica en su informe que la disposición penal de la Ley sobre el comercio de madera y productos de la madera es subsidiaria de los delitos de protección de especies, que contemplan penas más elevadas.

5) En el mismo sentido, Alemania indica en su informe nacional que pueden ser de aplicación otras figuras del Código Penal con penas más elevadas.

6) Noruega informa sobre la previsión de sanciones penales y administrativas, si bien no concreta ni su naturaleza ni su duración.

Como indicaba más arriba, identificar las penas máximas privativas de libertad en cada Estado miembro es interesante al efecto de determinar la posible aplicación de la Convención de las Naciones Unidas contra la delincuencia organizada transnacional (2004), que exige que los delitos sean punibles con una pena de privación de libertad máxima de al menos cuatro años.

De los resultados obtenidos, podría concluirse que dicha aplicación es únicamente posible en los Países Bajos. Sin embargo, las observaciones hechas con relación a Suecia y Alemania son indicativas del carácter precipitado que tendría tal aseveración. Las penas privativas de libertad objeto de análisis son estrictamente las previstas por infracción de las específicas obligaciones del EUTR, pero hay que tener presente que, en los distintos países, pueden ser aplicables otras normas penales al fenómeno de la tala y el tráfico ilegal de madera. Sobre esta cuestión volveré más adelante.

\section{ii. Sanciones pecuniarias}

Lamentablemente las fuentes de información disponibles no permiten discriminar, en todos los casos, entre multas penales y administrativas, a pesar de que en el modelo de informe bienal que deben cumplimentar los Estados 
miembros, se solicita que se indique la naturaleza de la sanción. Es por ello que en materia de sanciones pecuniarias, no puedo sino limitarme a remitirme al Informe Bienal de la Comisión que ofrece un análisis integrado de las multas aplicables a las infracciones del EUTR, a partir de la información facilitada por 25 países $^{32}$.

En el siguiente gráfico, que proporciona el mismo informe, se pueden ver las sanciones pecuniarias máximas impuestas a los agentes como consecuencia de infracciones del EUTR relacionadas con las obligaciones de diligencia debida, la prohibición de comercializar madera aprovechada ilegalmente y productos derivados de dicha madera y la obligación de trazabilidad en toda la cadena de suministro, cuando así se especificó en los informes nacionales.

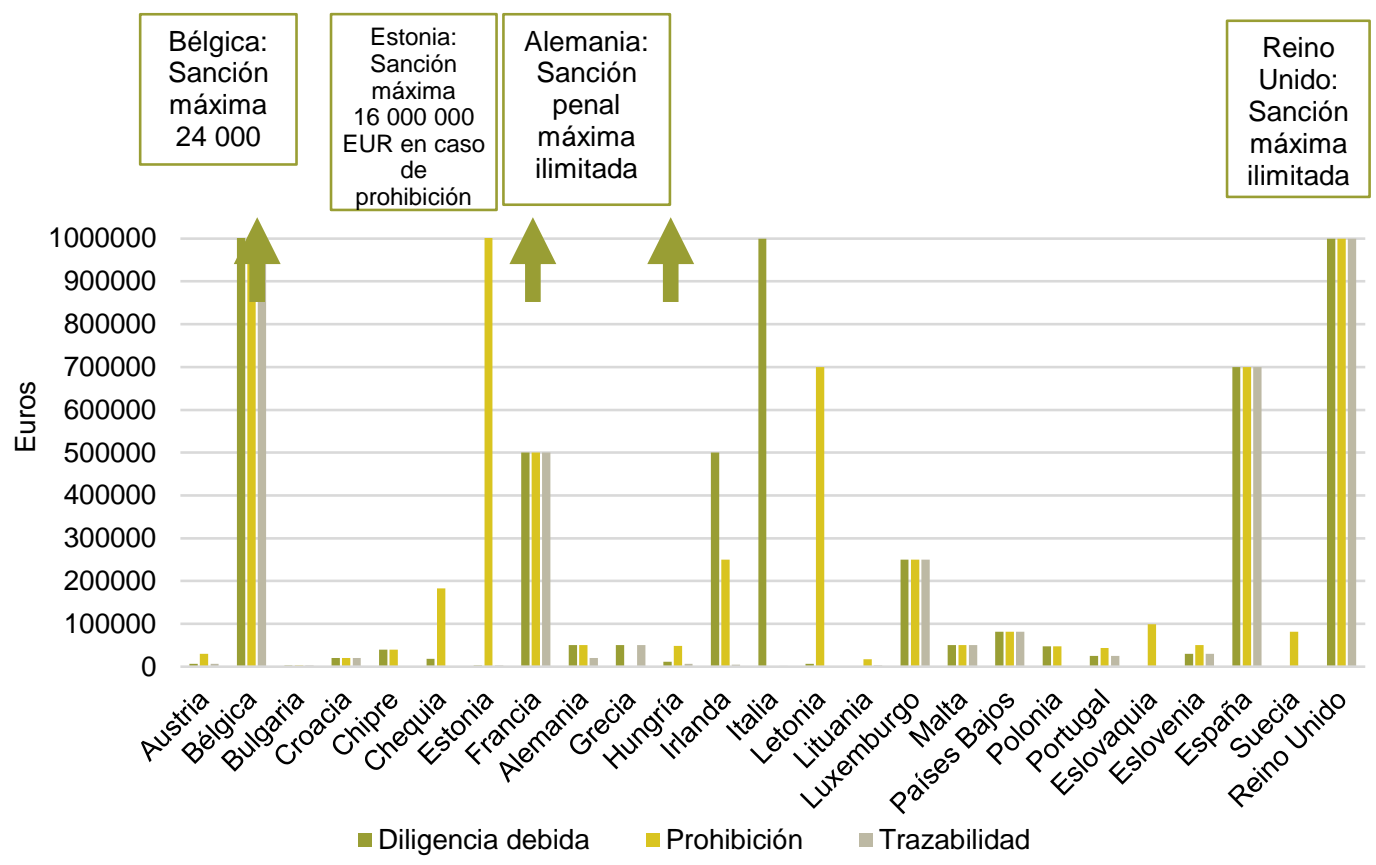

Figura 3 (fuente: Informe bienal para el período de marzo de 2015 a febrero de 2017 de la Comisión al Parlamento Europeo y al Consejo sobre la aplicación del EUTR): sanciones pecuniarias máximas impuestas a los agentes como consecuencia de infracciones del EUTR.

32 Informe de la Comisión al Parlamento Europeo y al Consejo. Reglamento (UE) n. ${ }^{\circ}$ 995/2010 del Parlamento Europeo y del Consejo, de 20 de octubre de 2010, por el que se establecen las obligaciones de los agentes que comercializan madera y productos de la madera (el Reglamento de la UE sobre la madera). Informe bienal para el período de marzo de 2015 a febrero de 2017, cit., p. 4 y 5. 
Como sintetiza el mismo informe, las multas van desde 14 euros hasta sanciones de cuantía ilimitada, siendo las más elevadas las relacionadas con la prohibición de comercializar en el mercado de la UE madera aprovechada ilegalmente y productos derivados de dicha madera. En concreto:

- Hasta 100.000 EUR: Alemania (sanciones administrativas), Austria, Bulgaria, Chipre, Croacia, Eslovaquia, Eslovenia, Grecia, Hungría, Lituania, Malta, Países Bajos, Polonia, Portugal y Suecia.

- Hasta 1.000.000 EUR: Chequia, España, Francia, Irlanda, Italia, Letonia y Luxemburgo.

- Más de 1.000.000 EUR: Alemania (sanciones penales), Bélgica, Estonia, y Reino Unido.

Como observaciones específicas, se hace constar:

1) Dinamarca informó de que no había fijado ningún límite.

2) Finlandia y Suecia, en información adicional solicitada, informaron que el importe de las multas se basa en los ingresos de los infractores.

3) La multa máxima en el Reino Unido es de cuantía ilimitada, tal como sucede en Alemania en el caso de las sanciones penales (las cifras indicadas solo se aplican a las sanciones administrativas).

La evaluación del carácter "efectivo, proporcionado y disuasorio" de las sanciones previstas en los distintos Estados miembros por infracción del EUTR, requiere un estudio específico sobre la aplicación de las mismas, que escapa a los objetivos de este trabajo. Sin embargo, debe apuntarse que, como ha sido ya denunciado, es más bien escasa la información pública disponible, a pesar de las obligaciones derivadas de la Directiva 2003/4/CE del Parlamento Europeo y del Consejo, de 28 de enero de 2003, relativa al acceso del público a la 
información medioambiental ${ }^{33} y^{34}$. Los informes bienales de los Estados miembros, tampoco cumplen siempre esta función, pues no todos los Estados miembros refieren desgraciadamente esta información.

\section{Breve apunte: sanciones penales más allá del EUTR}

Desde el punto de vista de las estrategias sancionadoras en materia de tráfico ilegal de madera, es importante tener en cuenta que, más allá de las sanciones derivadas del Reglamento EUTR, pueden ser de aplicación otras normas penales, ya sea directamente relacionadas con la protección del medio ambiente (delitos forestales, delitos contra la flora y la fauna, delito de contrabando), ya sea con relación a los distintos delitos que, de forma conexa, se cometen en un contexto de crimen ambiental organizado transnacional (evasión fiscal, blanqueo de capitales, delitos vinculados a la corrupción, etc.).

A su vez, tales normas penales pueden ser consecuencia de tratados internacionales, de normas europeas o tratarse de normas penales adoptadas por los Estados miembros de la UE en el ejercicio de su "ius puniendi".

Como es lógico, no es posible hacer aquí un análisis exhaustivo de los sistemas penales de los 28 Estados miembros de la UE con relación a todos los delitos aplicables. Sin embargo, desde el punto de vista del recurso al Derecho penal en materia de tráfico ilegal de madera, resulta imprescindible hacer referencia a la ya citada Directiva 2008/99/CE relativa a la protección del medio ambiente mediante el Derecho Penal, cuyo plazo de transposición finalizó el 26 de diciembre de 2010.

El artículo 3 de la Directiva 2008/99/CE describe nueve conductas que los Estados miembros deben considerar delito en sus legislaciones nacionales, cuando sean ilícitas y se cometan dolosamente o, al menos, por imprudencia

\footnotetext{
33 Vid. ClientEarth, National EUTR penalties: are they sufficiently effective, proportionate and dissuasive?, Londres, 2018, p.9-10. Disponible en: < https://www.documents.clientearth.org/wpcontent/uploads/library/2018-03-02-national-eutr-penalties-are-they-sufficiently-effective-

proportionate-and-dissuasive-ce-en.pdf> [última consulta, 8 de octubre de 2019]. En este mismo informe pueden verse algunos ejemplos de sanciones pecuniarias impuestas en algunos países (p. 6).

${ }^{34}$ Directiva 2003/4/CE del Parlamento Europeo y del Consejo, de 28 de enero de 2003, relativa al acceso del público a la información medioambiental y por la que se deroga la Directiva 90/313/CEE del Consejo. Disponible en: < https://eur-lex.europa.eu/legalcontent/ES/ALL/?uri=CELEX\%3A32003L0004> [última consulta, 8 de octubre de 2019].
} 
grave. A efectos de esta Directiva, se entiende por "ilícita" la infracción de la legislación comunitaria especificada en los anexos de la Directiva, o de una ley, un reglamento de un Estado miembro o una decisión adoptada por una autoridad competente de un Estado miembro que dé cumplimiento a la misma. Interesa particularmente aquí el artículo 3, letras f) y g) de la Directiva, según el cual, debe sancionarse penalmente en todos los Estados miembros de la UE:

“f) la matanza, la destrucción, la posesión o la apropiación de especies protegidas de fauna o flora silvestres, a excepción de los casos en los que esta conducta afecte a una cantidad insignificante de estos ejemplares y tenga consecuencias insignificantes para el estado de conservación de su especie;

g) el comercio de ejemplares de especies protegidas de fauna y flora silvestres o de partes o derivados de los mismos, a excepción de los casos en los que esta conducta afecte a una cantidad insignificante de estos ejemplares y tenga consecuencias insignificantes para el estado de conservación de su especie".

Aunque estos delitos no sean aplicables a todos los supuestos de destrucción, posesión o comercialización de madera aprovechada ilegalmente o de productos derivados de esta madera, sí lo son en aquellos supuestos en los que la madera esté catalogada como especie protegida de flora silvestre, ampliando así las posibilidades sancionadoras en esta materia de forma complementaria al EUTR. En concreto, entre las definiciones del artículo 2 de la Directiva, se establece que a los efectos del artículo $3 \mathrm{~g}$ ), se entenderá por "especies de flora y fauna silvestre", las recogidas en los anexos A y B del Reglamento (CE) núm. 338/97 del Consejo, de 9 de diciembre de 1996, relativo a la protección de especies de la fauna y flora silvestres mediante el control de su comercio ${ }^{35}$. El Reglamento 338/97 sustituyó el Reglamento (CEE) núm. 3626/82, que supuso, a su vez, la aplicación en la Comunidad, de la Convención sobre el comercio internacional

\footnotetext{
${ }^{35}$ Reglamento (CE) no 338/97 del Consejo, de 9 de diciembre de 1996, relativo a la protección de especies de la fauna y flora silvestres mediante el control de su comercio. Disponible en: <https://eur-lex.europa.eu/legal-content/ES/TXT/?uri=OJ:L:1997:061:TOC> [última consulta, 8 de julio de 2019].
} 
de especies amenazadas de fauna y flora silvestres, hecho en Washington el 3 de marzo de 1973 (CITES) ${ }^{36}$.

Es por ello que, a los efectos de tener una imagen más completa de la estrategia sancionadora penal en materia de cambio climático y de tráfico de madera en particular, es importante integrar los resultados de la implementación del artículo 19 EUTR con los resultados de la implementación del artículo 3 de la Directiva 2008/99/CE, en los distintos Estados miembros. Para ello me remito al trabajo previo ya citado, en el que tuve la oportunidad de hacer un análisis comparativo de las sanciones penales previstas por los distintos Estados miembros para cada uno de los delitos de la Directiva 2008/99/CE ${ }^{37}$.

Cabe señalar que es precisamente el carácter parcial de la protección que la Directiva 2008/99/CE procura en esta materia, lo que ha motivado que el propio Parlamento Europeo pidiera en 2018 a la Comisión Europea la ampliación de su ámbito de aplicación, "a fin de incluir en él la explotación ilegal de la madera"38.

Sin más información sobre esta petición, cabe hacer un par de consideraciones generales. En primer lugar, desde el punto de vista de las conductas delictivas, la expresión "explotación ilegal" incluiría todas las conductas que forman parte de la cadena delictiva en los delitos de tala y comercio ilegal de la madera y sus productos derivados, ya fuera con origen dentro o fuera de la UE. En segundo lugar, debería ampliarse el objeto de protección, pues como se ha apuntado, actualmente se refiere únicamente a especies protegidas. Esta última ampliación sería especialmente relevante a los efectos de desarrollar una estrategia

\footnotetext{
36 Convención sobre el comercio internacional de especies amenazadas de fauna y flora silvestres, hecho en Washington el 3 de marzo de 1973 (publicado en el BOE núm. 181, de 30 de julio de 1986, páginas 27045 a 27067). Disponible en: $<$ https://www.boe.es/buscar/doc.php?id=BOE-A-1986-20403> [última consulta, 8 de julio de 2019].

${ }^{37}$ Como se ha indicado más arriba, el análisis comparativo completo de las sanciones penales puede consultarse en Maria Marquès-Banqué, "The utopia of the harmonization of legal frameworks to fight against transnational organized environmental crime", cit., passim. Este análisis forma parte de un estudio más amplio sobre la implementación de la Directiva 2008/99/CE, realizado en el marco del proyecto coordinado por SEO/Birdlife para crear la "European Network against Environmental Crime (ENEC)", financiado por la Dirección General de Justicia de la Comisión Europea y cuya coautora es Núria Torres Rosell. Disponible en: https://www.eufje.org/images/docPDF/Study-on-the-implementation-of-Directive-

2008_99_ENEC_SEO_BirdLife_May2016.pdf [última consulta, 24 de septiembre de 2019].

38 Vid. la Resolución del Parlamento Europeo, de 11 de septiembre de 2018, sobre la gestión transparente y responsable de los recursos naturales en los países de desarrollo: los bosques cit., núm. 84.
} 
sancionadora penal en materia de cambio climático, pues significa un cambio de enfoque en la configuración del bien jurídico protegido, que dejaría de ser la biodiversidad (o únicamente la biodiversidad). Sobre ello volveré más adelante, cuando aborde esta misma cuestión con relación a España.

\section{LA PERSECUCIÓN PENAL DEL TRÁFICO ILEGAL DE MADERA EN ESPAÑA}

\section{La implementación normativa del artículo 19 EUTR en España}

España se encuentra entre los países que optaron por sancionar administrativamente la infracción de las obligaciones impuestas por el Reglamento EUTR y lo hizo, con dos años de retraso respecto a la fecha de aplicabilidad del Reglamento, a través de la Ley 21/2015, de 20 de julio, por la que se modifica la Ley $43 / 2003$, de 21 de noviembre, de Montes. Pocos meses después se promulgó el Real Decreto 1088/2015, de 4 de diciembre, para asegurar la legalidad de la comercialización de madera y productos de madera.

En materia de infracciones y sanciones, como indica el preámbulo de la Ley 21/2015:

"se introduce una nueva infracción por violación de los preceptos derivados de la aplicación del Reglamento n. 995/2010 del Parlamento Europeo y del Consejo, de 20 de octubre, sobre aseguramiento de la legalidad de los productos de madera, y la normativa europea derivada, cuestión que tiene reserva de ley. En ella el valor de la madera introducida en el mercado contraviniendo la normativa es el que define la gravedad de la infracción.

Para desincentivar la posibilidad de que la sanción se considere un coste más de una operación, pese a lo cual siga resultando rentable, se introduce el factor de que la sanción será la mayor de la prescrita o el doble del valor del daño causado (o de la madera comercializada, que además se confisca), junto con la obligación de reparar los daños, por lo que los casos en que a pesar de ello la infracción sea rentable, se eliminan en su práctica totalidad". 
En concreto, la Ley 21/2015 añade una nueva letra r) al artículo 67, considerando infracción administrativa:

"El incumplimiento de las obligaciones impuestas por el Reglamento (UE) núm. 995/2010 del Parlamento Europeo y del Consejo, de 20 de octubre de 2010, por el que se establecen las obligaciones de los agentes que comercializan madera y productos de la madera, en cuanto a:

1.. La comercialización de madera no aprovechada legalmente y sus productos derivados.

2.. La ausencia de mantenimiento y evaluación de un sistema de diligencia debida, ya sea de manera individual o a través de una entidad de supervisión.

3.․ㄴ La ausencia de colaboración con la Administración competente en los controles realizados por ésta.

4.ㄴ La no adopción de medidas correctoras expedidas, en su caso, por la autoridad competente tras la realización del correspondiente control.

5.․ El incumplimiento de la obligación de trazabilidad y conservación de esta información a la que están sujetos los comerciantes."

La clasificación de las infracciones y el régimen de sanciones es como sigue:

\begin{tabular}{|l|l|l|l|}
\hline $\begin{array}{l}\text { Clasificación de la } \\
\text { infracción (art. 68) }\end{array}$ & $\begin{array}{l}\text { Valor de la madera } \\
\text { objeto } \\
\text { incumplimiento }\end{array}$ & $\begin{array}{l}\text { Cuantía de la multa } \\
\text { (art. 74) }\end{array}$ & $\begin{array}{l}\text { Sanciones } \\
\text { accesorias } \\
\text { (art. 68) }\end{array}$ \\
\hline Muy grave & $>200.000$ euros & $\begin{array}{l}\text { de } 100.001 \text { a } \\
1.000 .000 \text { euros, } \\
\text { salvo que el importe } \\
\text { de la madera } \\
\text { indebidamente } \\
\text { comercializada, o el } \\
\text { doble del coste de } \\
\text { reposición del daño } \\
\text { causado, fueran } \\
\text { superiores al millón } \\
\text { establecer el } \\
\text { comiso de los } \\
\text { bienes los } \\
\text { comercializados } \\
\text { que constituyen }\end{array}$ \\
\hline
\end{tabular}




\begin{tabular}{|c|c|c|c|}
\hline & & caso, la sanción será & el objeto de la \\
\hline & & $\begin{array}{l}\text { equivalente al } \\
\text { importe mayor }\end{array}$ & $\begin{array}{l}\text { infracción, que } \\
\text { serán }\end{array}$ \\
\hline Grave & $\begin{array}{l}\leq 200.000 \text { euros pero } \\
>50.000 \text { euros }\end{array}$ & $\begin{array}{l}\text { de } 1.001 \text { a } 100.000 \\
\text { euros }\end{array}$ & $\begin{array}{l}\text { enajenados por } \\
\text { subasta pública }\end{array}$ \\
\hline Leve & $\leq 50.000$ euros & de 100 a 1.000 euros & \\
\hline
\end{tabular}

Tabla 1 (elaboración propia): Clasificación de las infracciones y régimen de sanciones por infracciones del EUTR previstas en la Ley 43/2003, de 21 de noviembre, de Montes.

Aquí también, la evaluación del carácter "efectivo, proporcionado y disuasorio" de las sanciones administrativas previstas en España por infracción del EUTR, requiere un estudio específico sobre la aplicación de las mismas. Cabe adelantar, sin embargo, que en el Informe bienal 2015-2017, enviado por España a la Comisión Europea, no se refirió ninguna sanción, ni tampoco existe jurisprudencia al respecto hasta la fecha ${ }^{39}$. Deberá esperarse a la publicación del informe correspondiente al periodo 2017-2019, para poder valorar, en su caso, la estrategia sancionadora adoptada por España en esta materia.

\section{Breve apunte: sanciones penales más allá del EUTR}

La opción de España por sancionar administrativamente la infracción de las obligaciones impuestas por el Reglamento EUTR, no descarta sin más la aplicación de sanciones penales en materia de tráfico ilegal de madera. Como se indicaba más arriba, más allá de las sanciones derivadas del Reglamento EUTR, pueden ser de aplicación otras normas penales relacionadas con la protección del medio ambiente o con el conjunto de delitos asociados que suelen darse en un contexto de crimen ambiental organizado transnacional.

\footnotetext{
39 Vid. Biennial Report (Government of Spain), p. 14. Disponible en: https://ec.europa.eu/environment/forests/pdf/biennial-reports-2017/ES\%20\%20EUTR\%20report.pdf [última consulta, 7 de octubre de 2019].
} 
Algunos Estados miembros (como Suecia y Alemania) así lo hicieron constar de forma expresa en los Informes bienales remitidos a la Comisión Europea ${ }^{40}$. Sin embargo, España, en el Informe bienal 2015-2017, dejó en blanco el apartado del Informe que pedía de forma expresa información sobre "otras sanciones aplicables a las infracciones del EUTR", y tampoco aprovechó para informar sobre la posibilidad de aplicar sanciones penales en el apartado (no obligatorio) en el que se preguntaba por las sanciones aplicables en el caso de infracciones comparables, entre las que se sugería las derivadas de la infracción del convenio CITES, al que me referiré más adelante ${ }^{41}$.

Sin embargo, como es sabido, en España rige el principio de preferencia del orden jurisdiccional penal (art. 44 de la Ley Orgánica 6/1985, de 1 de julio, del Poder Judicial). La misma Ley de Montes, como no podría ser de otra manera, así lo recuerda en su artículo 72 (aunque con una referencia no actualizada a las faltas), concretando además las consecuencias prácticas de la aplicación del principio "ne bis in idem":

"1. Cuando la infracción pudiera ser constitutiva de delito o falta, la Administración instructora lo pondrá en conocimiento del órgano jurisdiccional competente, suspendiéndose la tramitación del procedimiento sancionador mientras la autoridad judicial no hubiera dictado sentencia firme o resolución que ponga fin al proceso.

2. La sanción penal excluirá la imposición de sanción administrativa en los casos en que se aprecie la identidad del sujeto, del hecho y del fundamento. De no haberse estimado la existencia de delito o falta, el órgano competente continuará, en su caso, el expediente sancionador teniendo en cuenta los hechos declarados probados en la resolución firme del órgano judicial competente".

\footnotetext{
${ }^{40}$ Como se ha indicado más arriba, Suecia indica en su informe que la disposición penal de la Ley sobre el comercio de madera y productos de la madera es subsidiaria de los delitos de protección de especies, que contemplan penas más elevadas. En el mismo sentido, Alemania indica en su informe nacional que pueden ser de aplicación otras figuras del Código Penal con penas más elevadas.

41 Informe bienal para el periodo 2015-2017, remitido por el Gobierno de España a la Comisión Europea. Disponible en: <http://ec.europa.eu/environment/forests/pdf/biennial-reports2017/ES\%20-\%20EUTR\%20report.pdf> [última consulta, 8 de julio de 2019].
} 
Por todo ello, en los siguientes epígrafes apuntaré la posible aplicación de sanciones penales en el ámbito del tráfico ilegal de madera y sus productos derivados en España. En concreto, me referiré a la posible aplicación de los delitos de contrabando, así como del delito contra la flora previsto en el artículo 332 del Código Penal, haciendo especial hincapié en el objeto material de estas figuras delictivas. No se analizará, por desbordar el objetivo de este trabajo, ni cada uno de estos delitos de forma exhaustiva ni el conjunto de delitos asociados que se pueden cometer en contextos de criminalidad organizada.

\section{a) Los delitos de contrabando}

La aplicabilidad de la Ley Orgánica 12/1995, de 12 de diciembre, de Represión del Contrabando (en adelante, LORC) a algunas de las infracciones del EUTR fue en realidad sugerida por el propio Gobierno de España en el primer Informe bienal sobre la aplicación del EUTR remitido a la Comisión Europea ${ }^{42}$. Este primer informe, relativo al periodo 2013-2015, hace referencia al entonces Proyecto de reforma de la Ley de Montes, al Proyecto de Real Decreto para asegurar la legalidad de la comercialización de madera y productos de madera y a la LORC, si bien en el caso de ésta última parece referirse más a las infracciones administrativas que a los delitos de contrabando, en la medida que no se refieren penas privativas de libertad allí donde se informa sobre las sanciones aplicables. La referencia a la LORC desapareció completamente en el segundo Informe bienal (2015-2017), en el que, como he señalado más arriba, se informa ya únicamente sobre el régimen de infracciones y sanciones administrativas previstas en la Ley de Montes.

A pesar de tal omisión, lo cierto es que la LORC tipifica distintas figuras de contrabando aplicables al tráfico ilegal de madera y los productos derivados de esa madera.

Así, el artículo 2.2 LORC, tipifica como delito, siempre que el valor de los bienes, mercancías, géneros o efectos sea igual o superior a 50.000 euros, los que:

42 Disponible en: <http://ec.europa.eu/environment/forests/eutr_report.htm> [última consulta, 1 de octubre de 2019]. 
“b) Realicen operaciones de importación, exportación, comercio, tenencia, circulación de:

Géneros estancados o prohibidos, incluyendo su producción o rehabilitación, sin cumplir los requisitos establecidos en las leyes.

Especímenes de fauna y flora silvestres y sus partes y productos, de especies recogidas en el Convenio de Washington, de 3 de marzo de 1973,

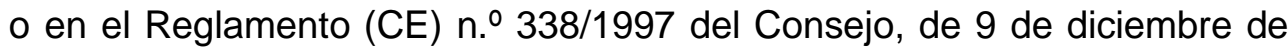
1996, sin cumplir los requisitos legalmente establecidos".

Es importante señalar que el requisito mínimo de 50.000 euros desaparece en determinadas circunstancias, de posible aplicación en el ámbito del tráfico ilegal de madera. Así, el artículo 2.3 LORC tipifica como delito de contrabando, con independencia del valor de los bienes, mercancías o géneros, la realización de estos mismos hechos cuando el objeto del contrabando sean bienes cuya tenencia constituya delito (lo cual, en el caso de la madera, nos remite al artículo 332 del Código penal) o cuando el contrabando se realice a través de una organización (lo cual nos remite a contextos de crimen organizado) ${ }^{43}$.

El artículo 2.4 LORC considera, además, que también comete delito de contrabando quien, en ejecución de un plan preconcebido o aprovechando idéntica ocasión, realizare una pluralidad de acciones u omisiones previstas en el artículo 2.2 LORC, en las que el valor de los bienes, mercancías, géneros o efectos aisladamente considerados no alcance el límite cuantitativo de 50.000 euros, pero cuyo valor acumulado sea igual o superior a dichos importes.

El artículo 2.5 LORC establece, a su vez, la punición de la comisión de los hechos por imprudencia grave y el artículo 2.6 LORC prevé la responsabilidad penal de las personas jurídicas "cuando concurran las circunstancias previstas en el artículo 31 bis de la Ley Orgánica 10/1995, de 23 de diciembre, del Código Penal y en las condiciones en él establecidas".

En cuanto a la penalidad, de acuerdo con el artículo 3 LORC, la comisión dolosa de los delitos de contrabando se castiga con las penas de prisión de uno a cinco

43 Sobre la interpretación del término "organización" como no necesariamente "criminal" en el sentido del artículo 570bis CP, vid. Patricia Faraldo Cabana, "Contrabando a través de una organización", en P. Faraldo Cabana (Dir.) y J.Á. Brandariz García (Coord.), Comentarios a la legislación penal especial, Lex Nova Thomson Reuters, Valladolid, 2012, p. 108 ss. 
años y multa del tanto al séxtuplo del valor de los bienes, mercancías, géneros o efectos, y la comisión imprudente con la pena inferior en un grado.

En el caso de las personas jurídicas, se prevé:

"a) En todos los casos, multa proporcional del duplo al cuádruplo del valor de los bienes, mercancías, géneros o efectos objeto del contrabando, y prohibición de obtener subvenciones y ayudas públicas para contratar con las Administraciones públicas y para gozar de beneficios e incentivos fiscales o de la Seguridad Social por un plazo de entre uno y tres años.

b) Adicionalmente, en los supuestos previstos en el artículo 2.2, suspensión por un plazo de entre seis meses y dos años de las actividades de importación, exportación o comercio de la categoría de bienes, mercancías, géneros o efectos objeto del contrabando; en los supuestos previstos en el artículo 2.3, clausura de los locales o establecimientos en los que se realice el comercio de los mismos".

La previsión de multas proporcionales tanto en el supuesto de personas físicas como de personas jurídicas es acorde con el artículo 19 del EUTR que, recordemos, establece que las sanciones deben ser efectivas, proporcionadas y disuasorias, sugiriendo como posibles medidas a adoptar las multas proporcionales y la incautación de la madera y de los productos de la madera de que se trate. Respecto a la incautación de la madera, debe señalarse que la LORC establece que toda pena que se impusiere por un delito de contrabando llevará consigo el comiso de los siguientes bienes, efectos e instrumentos:

"a) Las mercancías que constituyan el objeto del delito.

b) Los materiales, instrumentos o maquinaria empleados en la fabricación, elaboración, transformación o comercio de los géneros estancados o prohibidos.

c) Los medios de transporte con los que se lleve a efecto la comisión del delito, salvo que pertenezcan a un tercero que no haya tenido participación en aquél y el Juez o el Tribunal competente estime que dicha pena accesoria resulta desproporcionada en atención al valor del medio de transporte objeto del comiso y al importe de las mercancías objeto del contrabando.

d) Las ganancias obtenidas del delito, cualesquiera que sean las transformaciones que hubieran podido experimentar. 
e) Cuantos bienes y efectos, de la naturaleza que fueren, hayan servido de instrumento para la comisión del delito".

Con relación a las conductas previstas en el artículo 2.2 LORC, dos son las ideas que me interesa apuntar brevemente aquí:

A) En primer lugar, hay que señalar que, con relación al tráfico ilegal de madera o de sus productos derivados, la protección ofrecida por la LORC no se limita, como pudiera parecer a partir de una primera lectura, a las especies recogidas en CITES o en el Reglamento (CE) № 338/1997 relativo a la protección de especies de la fauna y flora silvestres mediante el control de su comercio.

Es importante hacer hincapié en que el artículo 2.2 LORC también hace referencia, como hemos podido ver, a operaciones de importación, exportación, comercio, tenencia o circulación de géneros estancados o prohibidos. La clave está en el concepto "géneros prohibidos" que el artículo 1 LORC define como:

"todos aquellos cuya importación, exportación, circulación, tenencia, comercio o producción estén prohibidos expresamente por tratado o convenio suscrito por España, por disposición con rango de ley o por reglamento de la Unión Europea. El carácter de prohibido se limitará para cada género a la realización de la actividad o actividades que de modo expreso se determinen en la norma que establezca la prohibición y por el tiempo que la misma señale".

Por consiguiente, ya sea por remisión a la Ley de Montes, ya sea por remisión al propio EUTR, deberá considerarse "género prohibido" toda madera no aprovechada legalmente y sus productos derivados, independientemente del carácter protegido o no de la especie. En esta misma línea, con relación a la remisión expresa del artículo 2.2 letra f) LORC a las especies CITES y del Reglamento (CE) núm. 338/1997, la doctrina ya había señalado que la inclusión de este objeto material no era necesaria, puesto que "la inclusión de una especie en el Apéndice I del Convenio CITES o en los Anexos A y B del Reglamento (CE) núm. 338/1997 supone que su comercio está prohibido, autorizándose solo de manera excepcional, lo que permite argumentar que, de no estar expresamente 
previstos, se trataría de géneros prohibidos, mientras que las especies incluidas en el resto de apéndices son de lícito comercio" 44.

Interpretar correctamente el alcance de la aplicación de los delitos de contrabando al tráfico ilegal de madera y sus productos derivados, es esencial en el contexto de una estrategia de lucha contra la deforestación y el cambio climático.

B) En segundo lugar, la posible incardinación de determinados supuestos de tráfico de madera en la conducta relativa a "géneros prohibidos", nos remite así mismo a la cuestión del bien jurídico protegido por estos delitos, sobre la que cabe hacer alguna observación.

Como bien ha indicado la doctrina, si bien los delitos de contrabando tradicionalmente tenían como objeto de tutela el patrimonio de la Hacienda Pública o Erario Público, "la opinión dominante en la actualidad considera que no es posible hallar un único bien jurídico común a todas las modalidades delictivas y que, por tanto, el objeto de tutela deberá determinarse en concreto a la vista de cada una de las conductas que se tipifican" 45 .

Con relación a las modalidades típicas que son de interés aquí, es importante recordar que el Reglamento (CE) núm. 450/2008 del Parlamento Europeo y del Consejo, por el que se establece el Código Aduanero Comunitario (Código Aduanero Modernizado) incluyó de forma expresa en su artículo 2, la protección del medio ambiente como misión aduanera ${ }^{46}$. Este Reglamento fue sustituido posteriormente por el Reglamento (UE) $n$ • 952/2013 del Parlamento Europeo y del Consejo, de 9 de octubre de 2013, por el que se establece el código aduanero

\footnotetext{
${ }^{44}$ Vid. Patricia Faraldo Cabana, "Operaciones de importación, exportación, comercio, tenencia, circulación de géneros estancados y especímenes de flora y fauna silvestre", en P. Faraldo Cabana (Dir.) y J.Á. Brandariz García (Coord.), Comentarios a la legislación penal especial, Lex Nova Thomson Reuters, Valladolid, 2012, p. 78. Con anterioridad, como bien refiere esta autora, vid. Antonio Mateos Rodríguez-Arias, "La aplicación de la Ley de contrabando a la protección de especies animales protegidas", en La Ley núm. 3, 1994, pp. 864-870.

45 Vid. Carlos Martínez-Buján Pérez, "Determinaciones previas", en P. Faraldo Cabana (Dir.) y J.Á. Brandariz García (Coord.), Comentarios a la legislación penal especial, Lex Nova Thomson Reuters, Valladolid, 2012, p. 26.

46 Vid. Reglamento (CE) núm. 450/2008 del Parlamento Europeo y del Consejo, por el que se establece el Código Aduanero Comunitario (Código Aduanero Modernizado) Disponible en: $<$ https://www.boe.es/buscar/doc.php?id=DOUE-L-2008-81015> [Última consulta, 1 de octubre de 2019].
} 
de la Unión ${ }^{47}$, el cual mantiene la expresa referencia a la protección del medio ambiente.

En consecuencia, cuando estamos ante supuestos de contrabando de especies protegidas de flora silvestre, se puede interpretar que el delito protege la biodiversidad, como concreción del interés colectivo medio ambiente. Esta interpretación es perfectamente coherente con la consideración de la biodiversidad como bien jurídico protegido en los delitos relativos a la flora y la fauna del Código Penal ${ }^{48}$. Junto a la biodiversidad, se ha planteado si es objeto de protección de este delito la actividad de control de las autoridades aduaneras. Al respecto, "la doctrina mayoritaria reconoce que esa actividad de control se protege como instrumento para tutelar una serie de intereses de diversa naturaleza, que son los que constituyen los auténticos bienes jurídicos del delito de contrabando, entre los que se encuentra la biodiversidad" 49 .

La persecución del tráfico ilegal de madera y sus productos derivados a través de la vía de "géneros prohibidos", requiere partir de una configuración del bien jurídico medio ambiente en un sentido mucho más amplio y complejo. No se trataría ya de la biodiversidad sino de un bien jurídico ambiental de nuevo cuño relacionado con el cambio climático. La necesidad o no de configurar un bien jurídico protegido específicamente relacionado con el cambio climático (más allá del genérico y por ello problemático concepto "medio ambiente") merece desde luego una reflexión pausada, que será objeto de un trabajo posterior. Baste aquí con dejar apuntada la cuestión, pues es una de las líneas de discusión futuras que abre el análisis de las estrategias sancionadoras en materia de cambio climático.

\footnotetext{
47 Vid. Reglamento (UE) $n \circ$ 952/2013 del Parlamento Europeo y del Consejo, de 9 de octubre de 2013, por el que se establece el código aduanero de la Unión. Disponible en: https://eurlex.europa.eu/legal-content/ES/TXT/?uri=uriserv:OJ.L_.2013.269.01.0001.01.SPA [Última consulta, 1 de octubre de 2019].

48 Vid. por todos, Esther Hava García, Protección jurídica de la fauna y flora en España, Ed. Trotta, Madrid, 2000, p.53ss.; Fermín Morales Prats, "De los delitos relativos a la protección de la flora, fauna y animales domésticos", en G. Quintero Olivares (Dir.) y F. Morales Prats (Coord.), Comentarios al Código Penal Español, $7^{a}$ edición, Tomo II, Thomson Reuters Aranzadi, 2016, p. 839 ss.;

49 Vid. Patricia Faraldo Cabana, "Operaciones de importación, exportación, comercio, tenencia, circulación de géneros estancados y especímenes de flora y fauna silvestre", cit., p. 75 , con las referencias doctrinales que avalan tal afirmación.
} 
Con todo, y para terminar la reflexión en torno a la aplicabilidad de los delitos de contrabando en materia de tráfico ilegal de madera, puede afirmarse que, a la vista de la inexistencia de jurisprudencia, hasta la fecha no se ha desplegado esta estrategia sancionadora en España.

\section{b) El artículo 332 del Código Penal}

Me he referido en primer lugar a los delitos de contrabando porque el objeto material del delito, de acuerdo con la interpretación ofrecida, es más amplio y permite abordar mejor la lucha contra el tráfico ilegal de madera y sus productos derivados. Sin embargo, cuando se trate de especies protegidas de flora silvestre, será también aplicable, como ya he indicado, el delito relativo a la flora previsto en el artículo 332 del Código Penal.

El artículo 332 del Código Penal establece:

"1. El que, contraviniendo las leyes u otras disposiciones de carácter general, corte, tale, arranque, recolecte, adquiera, posea o destruya especies protegidas de flora silvestre, o trafique con ellas, sus partes, derivados de las mismas o con sus propágulos, salvo que la conducta afecte a una cantidad insignificante de ejemplares y no tenga consecuencias relevantes para el estado de conservación de la especie, será castigado con la pena de prisión de seis meses a dos años o multa de ocho a veinticuatro meses, e inhabilitación especial para profesión u oficio por tiempo de seis meses a dos años.

La misma pena se impondrá a quien, contraviniendo las leyes u otras disposiciones de carácter general, destruya o altere gravemente su hábitat.

2. La pena se impondrá en su mitad superior si se trata de especies o subespecies catalogadas en peligro de extinción.

3. Si los hechos se hubieran cometido por imprudencia grave, se impondrá una pena de prisión de tres meses a un año o multa de cuatro a ocho meses, e inhabilitación especial para profesión u oficio por tiempo de tres meses a dos años."

La redacción vigente del artículo 332 del Código penal es consecuencia de la Ley Orgánica 1/2015, de 30 de marzo, por la que se modificó el Código penal. 
La reforma de este delito se justificó por la necesidad de abordar una mejor transposición de la ya citada Directiva 2008/99/CE, de 19 de noviembre de 2008, relativa a la protección del medio ambiente mediante el Derecho Penal.

Como tuve ocasión de señalar en un trabajo previo, la reforma de 2015 del art. $332 \mathrm{CP}$ puede ser calificada como sustancial, pues afecta al objeto material del delito, la estructura típica del delito, las conductas punibles y la penalidad, siendo especialmente destacable la introducción del castigo de la comisión imprudente ${ }^{50}$.

Me voy a referir aquí únicamente a la cuestión del objeto material del delito, pues no es objetivo de este trabajo hacer un análisis exhaustivo de la reforma de este delito sino una breve reflexión acerca de su aplicabilidad al ámbito del tráfico ilegal de madera.

Mientras la redacción anterior a 2015 hacía referencia a acciones de destrucción o tráfico ilegal de "especies o subespecies de flora amenazada o sus propágulos", a partir de la reforma, objeto material del delito pasan a serlo las "especies protegidas de flora silvestre", haciéndose también referencia a sus partes, derivados y propágulos en el supuesto de tráfico. Hasta ahora, el término "especie amenazada" había sido considerado como elemento normativo del tipo, sin perjuicio de haberse exigido, además de la inclusión de la especie en los correspondientes catálogos estatal o autonómicos de especies amenazadas, la efectiva situación de amenaza como requisito de antijuridicidad material del delito ${ }^{51}$.

La sustitución del término "especies amenazadas" por el de "especies protegidas de flora silvestre" implica una importante ampliación del objeto material del delito, pues la referencia no será ya únicamente al Catálogo Español de Especies

\footnotetext{
50 Vid. Maria Marquès Banqué, "Delitos relativos a la protección de la flora, fauna y animales domésticos", en G. Quintero Olivares (Dir.), Comentario a la Reforma Penal de 2015, ThomsonAranzadi, 2015, pp. 667-683.

51 Vid. las SSTS núm. 829/1999, de 19 de mayo y núm. 2227/2001, de 29 de noviembre; SAP Sevilla (Sección $3^{a}$ ) núm. 487/2007, de 25 de octubre; SAP Tarragona (Sección 2a) núm. 206/2012, de 3 de mayo. En el mismo sentido de no interpretar el término "especie amenazada" en un sentido formalista, aunque invocando el principio de intervención mínima, vid. Pastora García Álvarez y Carmen López Peregrín, "Los delitos contra la flora, la fauna y los animales domésticos. Análisis doctrinal y jurisprudencial, con referencia a la reforma introducida por la LO 5/2010, de 22 de junio", Revista Electrónica de Ciencia Penal y Criminología. 2013, núm. 15-11, p. 11:5.
} 
Amenazadas y a los correspondientes catálogos autonómicos, sino también al más amplio Listado de Especies Silvestres en Régimen de Protección Especial, creado por la misma Ley 42/2007, de 13 de diciembre, del Patrimonio Natural y de la Biodiversidad y desarrollado por el Real Decreto 139/2011, de 4 de febrero, para el desarrollo del Listado de Especies Silvestres en Régimen de Protección Especial y el Catálogo Español de Especies Amenazadas.

De acuerdo con el Real Decreto 139/2011, cabe entender por especie silvestre en régimen de protección especial, toda "especie merecedora de una atención y protección particular en función de su valor científico, ecológico y cultural, singularidad, rareza, o grado de amenaza, argumentado y justificado científicamente; así como aquella que figure protegida en los anexos de las directivas y convenios internacionales ratificados por España, y que por cumplir estas condiciones sean incorporadas al Listado".

En este sentido, deber recordarse que, como he indicado más arriba, a los efectos del artículo 3, letras f) y g) de la Directiva 2008/99/CE, se entenderá por "especies de flora y fauna silvestre", las recogidas en los anexos A y B del Reglamento (CE) núm. 338/1997 del Consejo, de 9 de diciembre de 1996, relativo a la protección de especies de la fauna y flora silvestres mediante el control de su comercio que, a su vez, supone la aplicación en la UE de la Convención sobre el comercio internacional de especies amenazadas de fauna y flora silvestres, hecho en Washington el 3 de marzo de 1973 (CITES).

Esta circunstancia plantea la relación concursal existente entre el art. $332 \mathrm{CP}$ y los delitos previstos en el artículo 2.2 letra f), segundo inciso, de la LORC. En los supuestos de tráfico ilegal de especies CITES o del Reglamento (CE) núm. 338/97, se plantean distintas opciones. Si se sostiene la identidad de bien jurídico cabe considerarlo un concurso aparente de normas penales que deberá resolverse por el principio de alternatividad, aplicándose el precepto penal más grave (art. 8.4 CP), aunque también se ha sostenido el concurso de delitos, ya sea ideal o medial ${ }^{52}$. En la medida que he defendido la biodiversidad como bien jurídico protegido de la modalidad de contrabando del artículo 2.2 letra f),

\footnotetext{
52 Sobre las distintas opciones doctrinales, vid. Patricia Faraldo Cabana, "Operaciones de importación, exportación, comercio, tenencia, circulación de géneros estancados y especímenes de flora y fauna silvestre", cit., pp. 81-82.
} 
segundo inciso, de la LORC y la coherencia en este punto con el artículo 332 $\mathrm{CP}$, comparto que el concurso deberá resolverse como concurso aparente de normas penales con aplicación del principio de alternatividad. La determinación del precepto más grave dependerá de las circunstancias concomitantes al caso y de la posible apreciación de supuestos agravados, debiéndose recordar que el eventual concurso no se presentará en todos los supuestos de tráfico ilegal de especies de flora CITES o del Reglamento (CE) núm. 338/97, pues, en el caso de la LORC, opera el requisito mínimo de 50.000 euros del valor de los bienes, mercancías, géneros o efectos objeto de contrabando, cuando no se da ninguna de las circunstancias que lo suprimen.

Como en el caso de la LORC, debe concluirse que, a pesar de la aplicabilidad del art. $332 \mathrm{CP}$ en la persecución del tráfico ilegal de madera y sus productos derivados, lo cierto es que tampoco se ha desplegado esta estrategia sancionadora en España. La jurisprudencia relativa al artículo 332 CP se refiere en pocas ocasiones a supuestos vinculados a la madera y, cuando es así, suele tratar casos de tala no autorizada de árboles que, en muchas ocasiones, terminan en absolución o sobreseimiento por no tratarse de especies protegidas $^{53}$.

\section{CONCLUSIONES}

El objetivo de este trabajo era analizar la implementación normativa del marco sancionador del EUTR en los Estados miembros de la UE y, en concreto, el recurso al Derecho penal, el nivel de armonización alcanzado y, en definitiva, la estrategia sancionadora seguida en la UE y, en particular, en España, en materia de tráfico ilegal de madera y sus productos derivados, como elemento relevante en la lucha contra el cambio climático.

Los resultados obtenidos del análisis en la UE, que deben valorarse conjuntamente con los resultados obtenidos en un trabajo anterior con relación a la Directiva 2008/99/CE, confirman un escenario de baja armonización de las sanciones que facilita la acción criminal, especialmente por parte de grupos

53 Vid., por ejemplo, SAP Córdoba núm. 553/2007, de 15 de octubre; SAP Soria núm. 22/2008, de 13 de mayo; AAP Madrid núm. 664/2008, de 30 de junio; AAP Valladolid núm. 181/2012, de 30 de marzo. 
organizados. Sin embargo, concluir de ahí y de forma automática la necesidad de recurrir al Derecho penal y, concretamente, a penas privativas de libertad elevadas, sería muy precipitado. Además de ser una cuestión que no puede valorarse al margen del rico y complejo debate que tiene lugar en materia de Derecho penal europeo, precisamente en el contexto europeo se insiste en la oposición al recurso indiscriminado al Derecho penal en el ámbito ambiental y se advierte de algo que comparto y que considero fundamental: de poco servirá armonizar las sanciones penales mientras no exista un sistema obligatorio de recolección de datos con relación a la persecución y sanción de los delitos ambientales en la UE, que permita evaluar racionalmente y sobre la base de datos empíricos la política criminal europea en materia ambiental ${ }^{54}$.

La necesidad de disponer de una base de datos que facilite el análisis del carácter eficaz, disuasorio y proporcionado de las sanciones previstas, es especialmente relevante en aquellos países en los que, como España, se ha optado exclusivamente por las sanciones administrativas para castigar las infracciones del EUTR. Estos países, ante la relevancia del interés protegido, deberían poder fundamentar muy bien la suficiencia de su régimen sancionador. El análisis de la implementación del EUTR en España no permite pensar que el legislador penal haya abordado de forma pausada tal reflexión. En este sentido, es indicativo que las vías señaladas en este trabajo para la persecución penal del tráfico ilegal de madera en España, no sean ni siquiera mencionadas en el Informe bienal 2015-2017 sobre implementación del EUTR enviado por España a la Comisión Europea, cuando así se podría haber hecho constar. En la medida que estamos hablando de estrategias sancionadoras en materia de cambio climático, en sede penal la reflexión debería empezar por el bien jurídico protegido, siendo ésta una de las líneas de investigación futura que se abren a partir de este trabajo. Es importante preguntarse, en una situación de crisis y emergencia climática como la actual, si además del bien jurídico biodiversidad

\footnotetext{
54 Vid. el interesante análisis y conclusiones de EFFACE, proyecto interdisciplinar europeo sobre delitos ambientales que analizó en profundidad la cuestión. Los informes y materiales del proyecto pueden consultarse en la página web del mismo: <http://efface.eu/> [última consulta, 10 de octubre de 2010]. Además, vid. los estudios de caso realizados en el contexto del proyecto en: Ragnhild Sollund; Christoph H. Stefes; Anna Rita Germani (Eds.), Fighting Environmental Crime in Europe and Beyond. The Role of the EU and Its Member States, Londres, Palgrave Macmillan, 2016.
} 
sobre el que se han configurado los delitos relativos a la flora y la fauna, las vías de persecución penal del tráfico ilegal de madera y de sus productos derivados, no deben plantearse desde una perspectiva más amplia, coherente con el rol fundamental que los bosques desempeñan en el sistema climático.

\section{BIBLIOGRAFÍA}

ClientEarth, National EUTR penalties: are they sufficiently effective, proportionate and dissuasive?, 2018. Disponible en: < https://www.documents.clientearth.org/wp-content/uploads/library/2018-03-02national-eutr-penalties-are-they-sufficiently-effective-proportionate-anddissuasive-ce-en.pdf> [última consulta, 8 de octubre de 2019].

Evashova, Yulia, "How effective is the New Timber Regulation in the Fight against Illegal Logging?", Review of European Community and International Environmental Law 20 (3) 2011, p.290-299.

Faraldo Cabana, Patricia, "Contrabando a través de una organización", en P. Faraldo Cabana (Dir.) y J.Á. Brandariz García (Coord.), Comentarios a la legislación penal especial, Lex Nova Thomson Reuters, Valladolid, 2012, p. 108111.

Faraldo Cabana, Patricia, "Operaciones de importación, exportación, comercio, tenencia, circulación de géneros estancados y especímenes de flora y fauna silvestre", en P. Faraldo Cabana (Dir.) y J.Á. Brandariz García (Coord.), Comentarios a la legislación penal especial, Lex Nova Thomson Reuters, Valladolid, 2012, p. 74-82.

Faure, Michael , "European Environmental Criminal Law: Do we really need it?", European Energy and Environmental Law Review, 13:1 (2004), p. 18-29.

Faure, Michael, "Effective, proportional and dissuasive penalties in the implementation of the Environmental Crime and Shipsource Pollution Directives: Questions and Challenges", European Energy and Environmental Law Review, 19:6 (2010), p. 256-278.

Faure, Michael, "The implementation of the environmental crime Directives in Europe", en J. Gerardu, D. Grabiel, MR. Koparova, K. Markowitz y D. Zaelke (eds), 9th International Conference on Environmental Compliance and Enforcement, Washington, INECE, 2011, p. 360-371.

Faure, Michael, "The revolution in environmental criminal law in Europe", Virginia Environmental Law Journal, 35:2 (2017), p. 321-356.

Faure, Michael; Svatikova, Katarina, "Criminal or administrative law to protect the environment? Evidence from Western Europe", Journal of Environmental Law, $24: 2$ (2012), p. 253-286.

García Álvarez, Pastora; López Peregrín, Carmen, "Los delitos contra la flora, la fauna y los animales domésticos. Análisis doctrinal y jurisprudencial, con referencia a la reforma introducida por la LO 5/2010, de 22 de junio", Revista Electrónica de Ciencia Penal y Criminología. 2013, núm. 15-11, p. 11:1-11:65. 
Global Initiative Against Transnational Organized Crime, Tightening the Net: Toward a Global Legal Framework on Transnational Organized Environmental Crime, 2015, p.34. Disponible en: shttps://www.unodc.org/documents/congress/background-

information/NGO/GIATOC-Blackfish/GIATOC_-_Tightening_the_Net.pdf> [última consulta, 30 de septiembre de 2019].

Hava García, Esther, Protección jurídica de la fauna y flora en España, Ed. Trotta, Madrid, 2000.

Marquès Banqué, Maria, "Delitos relativos a la protección de la flora, fauna y animales domésticos", en G. Quintero Olivares (Dir.), Comentario a la Reforma Penal de 2015, Thomson-Aranzadi, 2015, p. 667-683.

Marquès-Banqué, Maria, "Protección penal del medio ambiente en la Unión Europea. Luces y sombras", en P.M. De la Cuesta Aguado et al (coord.), Liber amicorum: estudios jurídicos en homenaje al profesor doctor Juan Ma. Terradillos Basoco, Tirant lo Blanch, Valencia, 2018, p. 1257-1270.

Marquès-Banqué, Maria, "The utopia of the harmonization of legal frameworks to fight against transnational organized environmental crime", Sustainability, Volume 10, Issue 10, 3576 (Special issue: Environmental Law for Sustainability 2018). Disponible en: <https://www.mdpi.com/2071-1050/10/10/3576> [última consulta, 8 de julio de 2019].

Martínez-Buján Pérez, Carlos, "Determinaciones previas", en P. Faraldo Cabana (Dir.) y J.Á. Brandariz García (Coord.), Comentarios a la legislación penal especial, Lex Nova Thomson Reuters, Valladolid, 2012, p. 23-27.

Mateos Rodríguez-Arias, Antonio, "La aplicación de la Ley de contrabando a la protección de especies animales protegidas", en La Ley núm. 3, 1994, p. 864870.

Morales Prats, Fermín, "De los delitos relativos a la protección de la flora, fauna y animales domésticos", en G. Quintero Olivares (Dir.) y F. Morales Prats (Coord.), Comentarios al Código Penal Español, $7^{\text {a }}$ edición, Tomo II, Thomson Reuters Aranzadi, 2016, p. 839-865.

Öberg, Jacob, "Criminal sanctions in the field of EU Environmental Law", New Journal of European Criminal Law, 2:4, (2011), p. 402-425.

Saunders, Jade; Reeve, Rosalind, The EU Timber Regulation and CITES, Energy, Environment and Resources PP EER 2014/08, Chatham House, London, 2014. Disponible en: < https://www.chathamhouse.org/publications/papers/view/199158\#> [última consulta, 11 de octubre de 2019].

Sollund, Ragnhild; Stefes, Christoph H.; Germani, Anna Rita (Eds.), Fighting Environmental Crime in Europe and Beyond. The Role of the EU and Its Member States, Londres, Palgrave Macmillan, 2016.

UNEP e INTERPOL. The environmental crime crisis. Threats to sustainable development from illegal exploitation and trade in wildlife and forest resources, 2014. Disponible en: <https://www.interpol.int/Crimes/Environmentalcrime/Forestry-crime> [última consulta, 9 de octubre de 2019]. 
UNODC, Herramientas para el análisis de los delitos contra la vida silvestre y los bosques, 2012.

Disponible

en: $<$ https://www.unodc.org/documents/Wildlife/Toolkit_s.pdf> [última consulta, 9 de octubre de 2019]. 